\title{
Downtown Los Angeles 52-Story High-Rise and Free-Field Response to an Oil Refinery Explosion
}

\author{
Monica D. Kohler, ${ }^{\text {a) }}$ M.EerI, Anthony Massari, ${ }^{\text {a) }}$ M.EerI, \\ Thomas H. Heaton, ${ }^{\text {a),b) }}$ M.EerI, Hiroo Kanamori, ${ }^{\text {b) Egill Hauksson, }}$, \\ Richard Guy, ${ }^{\text {b) }}$ Robert W. Clayton, ${ }^{\text {b) Julian Bunn, }}$ (c) and K. M. Chandy ${ }^{d}$
}

The ExxonMobil Corp. oil refinery in Torrance, California, experienced an explosion on 18 February 2015, causing ground shaking equivalent to a magnitude 2.0 earthquake. The impulse response for the source was computed from Southern California Seismic Network data for a single force system with a value of $2 \times 10^{5} \mathrm{kN}$ vertically downward. The refinery explosion produced an air pressure wave that was recorded $22.8 \mathrm{~km}$ away in a 52-story high-rise building in downtown Los Angeles by a dense accelerometer array that is a component of the Community Seismic Network. The array recorded anomalous waveforms on each floor displaying coherent arrivals that are consistent with the building's elastic response to a pressure wave caused by the refinery explosion. Using a finite-element model of the building, the force on the building on a floor-by-floor scale was found to range up to $1.42 \mathrm{kN}$, corresponding to a pressure perturbation of $7.7 \mathrm{~Pa}$. [DOI: 10.1193/062315EQS101M]

\section{INTRODUCTION}

The ExxonMobil Corp. oil refinery experienced an explosion on 18 February 2015 in Torrance, California, $20 \mathrm{~km}$ south of downtown Los Angeles (Figure 1). The explosion occurred in the morning and was caused by excess pressure buildup in the electrostatic precipitator, which is a pollution-monitoring device (Hsu 2015a, 2015B; Penn 2016). It destroyed a portion of a building and other structures on the refinery grounds and caused a partial shutdown of the facility. The explosion was heard and felt by nearby residents who reported ground shaking that knocked a TV off its stand and vibrations that shattered a garage window (Groom 2015).

The explosion was recorded by a few nearby Caltech/USGS Southern California Seismic Network (SCSN; Hutton et al. 2010) stations with ground motions equivalent to a magnitude 2.0 earthquake. Seismic networks have long been one of the most reliable

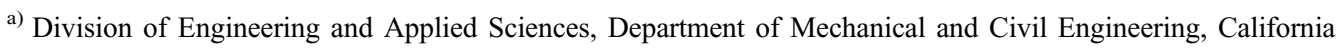
Institute of Technology, Pasadena, CA 91125

b) Division of Geological and Planetary Sciences, Seismological Laboratory, California Institute of Technology, Pasadena, CA 91125

c) Division of Physics, Math and Astronomy, California Institute of Technology, Pasadena, CA 91125

d) Division of Engineering and Applied Sciences, Department of Computing and Mathematical Sciences, California Institute of Technology, Pasadena, CA 91125
} 


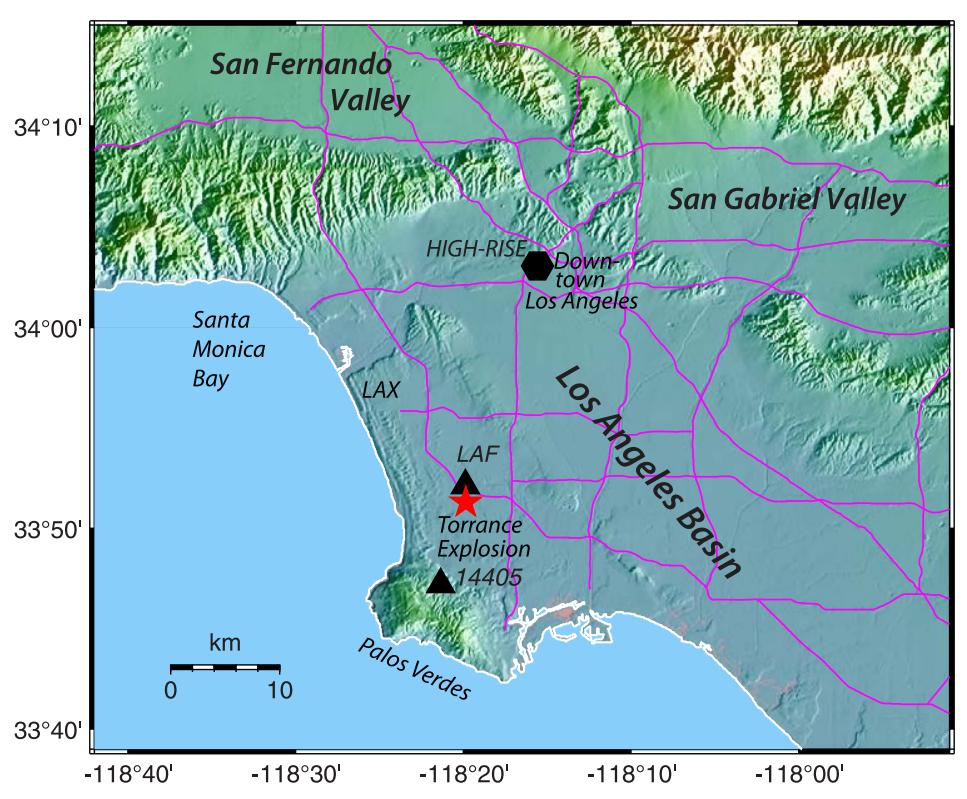

Figure 1. Map of greater Los Angeles region showing location of refinery explosion in Torrance, CA (red star), Southern California Seismic Network stations LAF and 14405 (black triangles), and Community Seismic Network-instrumented 52-story building in downtown Los Angeles (black hexagon). LAX: Los Angeles International Airport. Violet curves: major highways.

tools to determine the location and yield of nuclear explosions over large distances. Now, with denser sensor spacing and nearly instantaneous communication and processing speeds, it is possible to report in near real time on the location and size of much smaller explosions.

The 18 February 2015 refinery explosion in Torrance, CA also produced an air pressure wave that was recorded by a dense, vertically aligned, three-component accelerometer array installed in a 52-story high-rise building in downtown Los Angeles. This structural array instrumentation is a component of the Caltech-operated Community Seismic Network (CSN). This is the first known occurrence of a pressure wave having been recorded in an urban region, particularly with high spatial density (samples from every floor), at small spatial scale within a single structure ( $4 \mathrm{~m}$ between floors), and at a temporal sample rate of 50 samples per second (sps) from continuous waveform recording. Shortly following the explosion, the array recorded an anomalous set of coherent arrivals (Figure 2) that are explained by the building's elastic response to a pressure wave caused by the refinery explosion, propagation across the Los Angeles basin, and coupling with the external faces of the building.

The objectives of this study are several-fold. Because the real-time capability of the SCSN allows for immediate detection, location, and characterization of earthquakes, we show here how a similar analysis procedure can be applied to other vibration events such 


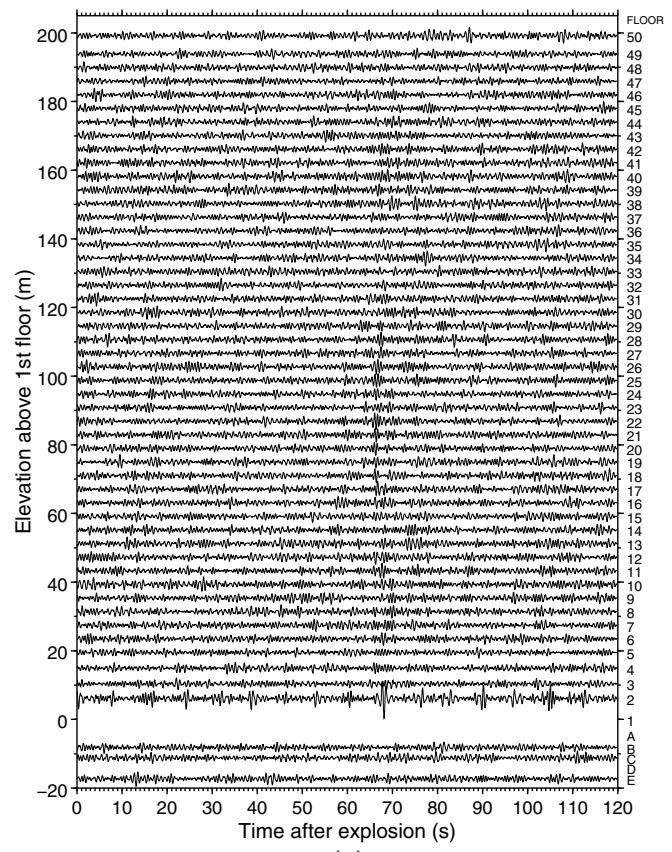

(a)

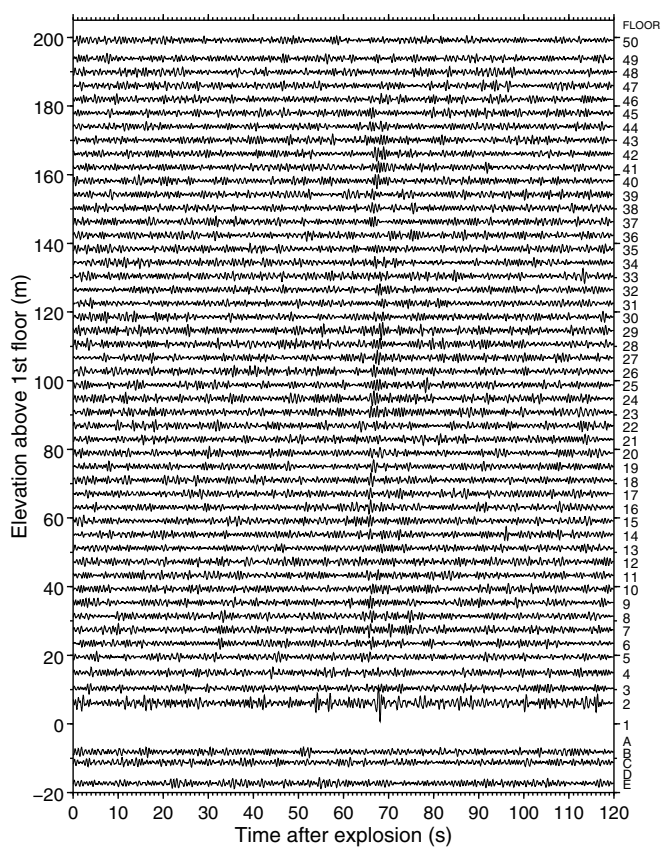

(b)

Figure 2. Acceleration time series [(a) north-south component, (b) east-west component] recorded in a 52-story building in downtown Los Angeles for up to $120 \mathrm{~s}$ after the occurrence of the Torrance refinery explosion. Pressure wave signal is apparent at $\sim 66 \mathrm{~s}$ after explosion time. Acceleration time series amplitudes are normalized by a constant $(13,000 \mathrm{~m} / \mathrm{g})$ in order to show amplitudes as a function of floor height (in meters), and to show relative floor-to-floor amplitudes. Floors for which data are not shown either had no installed sensor or had a faulty sensor recording at the time of the explosion.

as explosions. The continuous recording capability in buildings has enabled the recording of numerous small- and moderate-size earthquakes, which in turn leads to validation of the finite-element models for linear-elastic behavior. Using these validated models, we also show how the static condensation technique that leads to construction of a reduced finite-element building model, used to examine the computational response of buildings to earthquakes, can also be effectively applied to other vibration sources. Furthermore, we show how the density of building recordings, primarily used to examine earthquake shaking response on a floor-by-floor scale, can be used to identify the level and potential type of damage caused by anthropogenic hazards taking advantage of the same sensor technology as for earthquakes.

There is a long history of using seismic systems forensically after human-induced events, including terrorist attacks, to determine the precise time and size of the event. These determinations have employed traditional seismic systems, but now it is possible to quantify these parameters within a few minutes. 
Examples of using traditional seismic systems include the following:

- The 23 April 1995 Oklahoma City bombing was detected on seismometers in Oklahoma in which the magnitude of the explosion was estimated to be 3.0 (Holzer et al. 1996). After the terrorist attack, forensic seismologists estimated the size of the chemical explosion, essential facts in piecing together the entire set of events.

- The 10 August 1998 truck bomb attack on the U.S. Embassy in Nairobi was detected with a single nearby seismometer and the size of the explosion estimated (Koper et al. 1999).

- The September 11 attacks on the World Trade Center were recorded and confirmed by seismic sensors outside of New York City (Kim et al. 2001); there were no seismic sensors inside the city. The timeline of the events, including the impacts into both towers and their subsequent collapse, were recorded on seismic sensors $34 \mathrm{~km}$ from Ground Zero. The collapse of the North Tower was recorded on seismic sensors as far away as New Hampshire and was estimated to have a magnitude of 2.3 .

- The September 2010 San Bruno, California natural gas pipeline explosion was detected by nearby seismic sensors in Northern California (D. Oppenheimer, pers. comm., 2011).

In all of the above incidents, only a few seismic sensors without the aid of real-time communication and processing detected the explosions and building collapse, and were of little use as the emergency unfolded. Provided at least four SCSN seismic sensors detect an explosion, the SCSN can automatically report a location and equivalent earthquake magnitude within tens of seconds. If there is more than one explosion within a short time interval, the seismic data can be used to resolve individual events down to a temporal resolution of a second or less.

The SCSN seismic sensors routinely detect and report on quarry blasts, and in some cases construction-related blasts in Southern California. In the past, the seismic sensors have recorded several industrial explosions in Los Angeles, as well as the time of impact of the DC-9 airliner crashing into the ground following a mid-air collision above Orange County on 31 August 1986. Since 1994, the seismic sensors have recorded more than 129 sonic booms. It is critical to be able to distinguish seismic characteristics of an earthquake from those of explosions or sonic booms. The public notices most of these booms; to respond to public concerns, emergency responders need to know that these were not earthquakes. The 2015 Torrance refinery blast was equivalent to a very large sonic boom.

\section{MODELING THE EXPLOSION SOURCE}

The explosion that occurred on 18 February 2015 at 8:49:12 a.m. local time was located at $33.8550^{\circ}$ latitude and $-118.3310^{\circ}$ longitude in Torrance, California. The time and location of the event were computed by the SCSN using earthquake detection and location methods. The SCSN seismic station LAF (Figure 1) in the La Fresa neighborhood of Torrance at a distance of $1.54 \mathrm{~km}$ from the explosion site recorded ground accelerations of $0.057 \% \mathrm{~g}$, $0.053 \% g$, and $0.059 \% g$ for the east-west $(\mathrm{E})$, north-south $(\mathrm{N})$, and vertical $(\mathrm{Z})$ components, respectively (Figure $3 \mathrm{a}$ ). Figure $3 \mathrm{~b}$ shows the acceleration time series recorded at California 


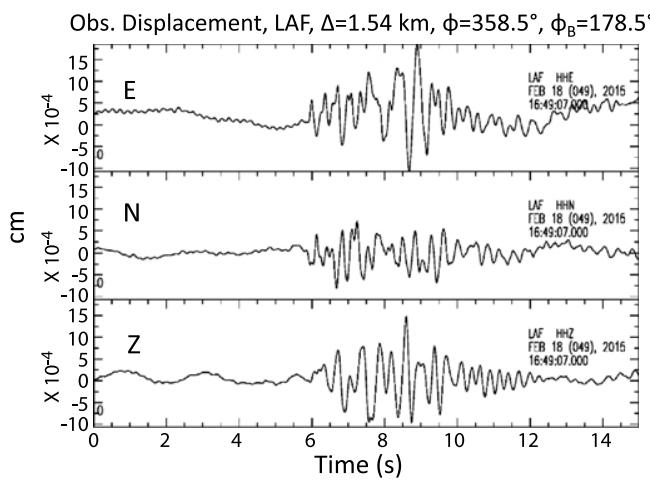

(a)

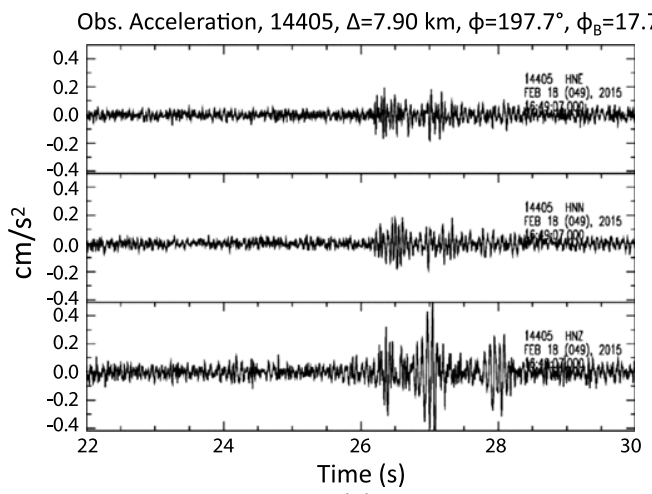

(b)

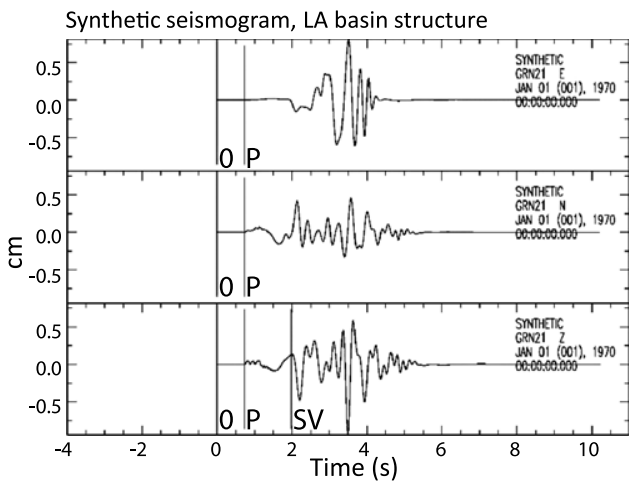

(c)

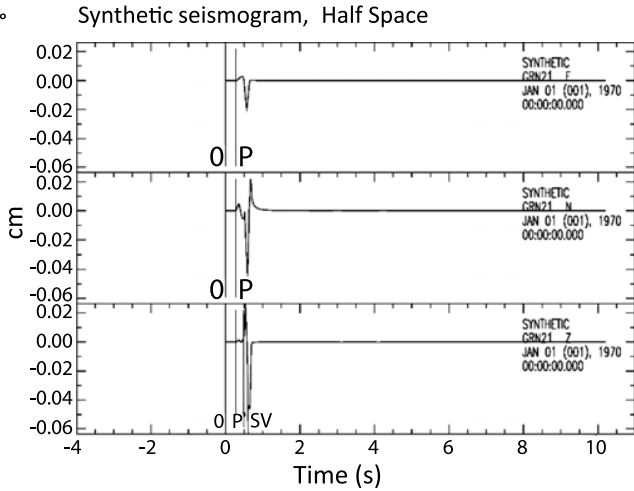

(d)

Figure 3. (a) Observed displacement at SCSN broadband seismic station LAF in Torrance, CA, at distance $\Delta=1.54 \mathrm{~km}$, azimuth $\phi=358.5^{\circ}$ (clockwise from north), and back-azimuth (clockwise from north) $\phi_{B}=178.5^{\circ}$. (b) Observed acceleration at SCSN strong-motion seismic station 14405 in Rolling Hills Estates, CA, with $\Delta=7.90 \mathrm{~km}, \phi=197.7^{\circ}, \phi_{B}=17.7^{\circ}$. (c) Synthetic seismogram computed for average Los Angeles basin seismic velocity structure (Table 1). The source force time history is a $0.1 \mathrm{~s}$ wide box car function with an amplitude of $10^{8} \mathrm{kN}$. (d) Synthetic seismogram computed for a homogeneous half space. The source is the same as that used for (c). Vertical lines marked "O," "P," and "SV" indicate times corresponding to explosion origin, P-wave arrival, and vertically polarized S-wave arrival, respectively.

Geological Survey (CGS) strong-motion station 14405 located in Rolling Hills Estates, California, at a distance of $7.9 \mathrm{~km}$ from the explosion site (Figure 1). Figure 4 shows the Fourier spectra of the three-component displacement records at station LAF and the vertical component of the acceleration record at station 14405. The signal observed at station 14405 (Figure 3b) can be either ground waves or air waves. From the arrival time of the highfrequency wave train, we estimate the wave speed to be $338 \mathrm{~m} / \mathrm{s}$, which is close to the average speed of sound in air. The dominant frequency of the wave train is about $13 \mathrm{~Hz}$ as shown in Figure 4d, and ground waves at such high frequency are most likely attenuated during propagation. Thus, we believe that the signal recorded at station 14405 is predominantly the air wave coming directly from the source. 
Fourier spectrum of displacement at LAF and acceleration (vertical component) at station 14405

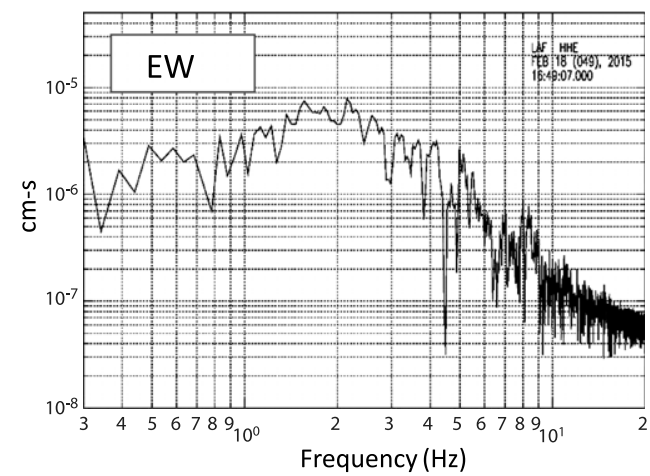

(a)

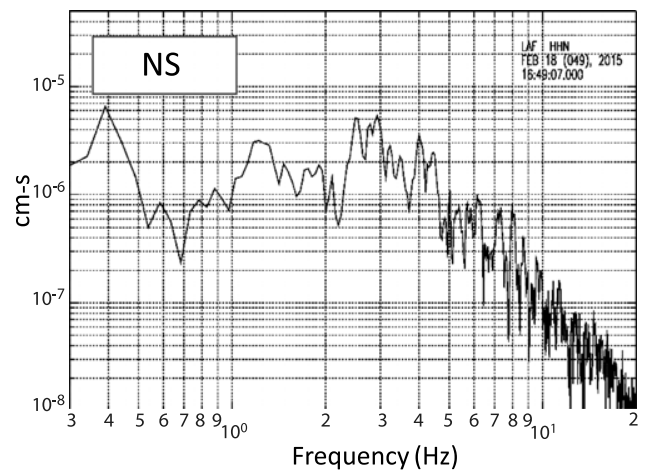

(b)

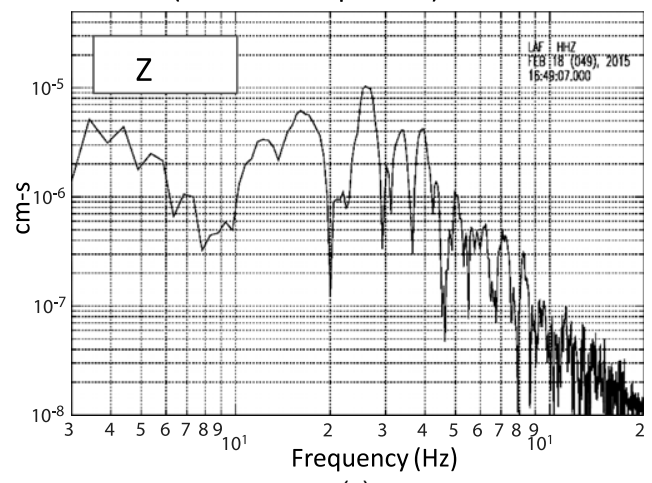

(c)

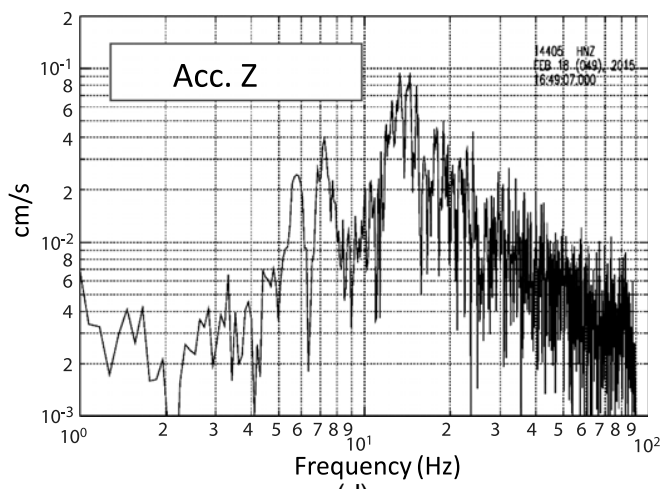

(d)

Figure 4. (a, b, c) Fourier spectra of the three-component displacement records at seismic station LAF and (d) of the vertical component of the acceleration record at station 14405.

We analyzed the LAF broadband waveforms (Figure 3a) to determine the explosion geometry, time, strength, and source dynamics. Since station LAF is located due north of the refinery, we interpret the displacements on the vertical and the north-south component as Rayleigh waves, and on the east-west component as Love waves. With a seismic observation at only one station, and without detailed knowledge about the structure of the explosion source area (e.g., size of the building, details of how the structures were damaged), we cannot determine the detailed geometry of the source. For the purpose of interpretation of seismic data, we envisage that the explosion took place over a surface area of radius $a$. If there is no structure on the side, this can be modeled by a single vertical force. A single vertical force can excite only Rayleigh waves. However, the seismic record at station LAF clearly shows Love waves represented by the transverse motion (i.e., east-west component). Thus, we added a horizontal force which could be produced by interaction of the explosion against the side walls. The amplitude ratio of the horizontal to the vertical force is 0.4 . Figure 5 illustrates a schematic of the explosion source characteristics.

We computed the waveforms for LAF using two velocity models: a homogeneous half space, and a velocity model that matched the local velocities of the near-surface 

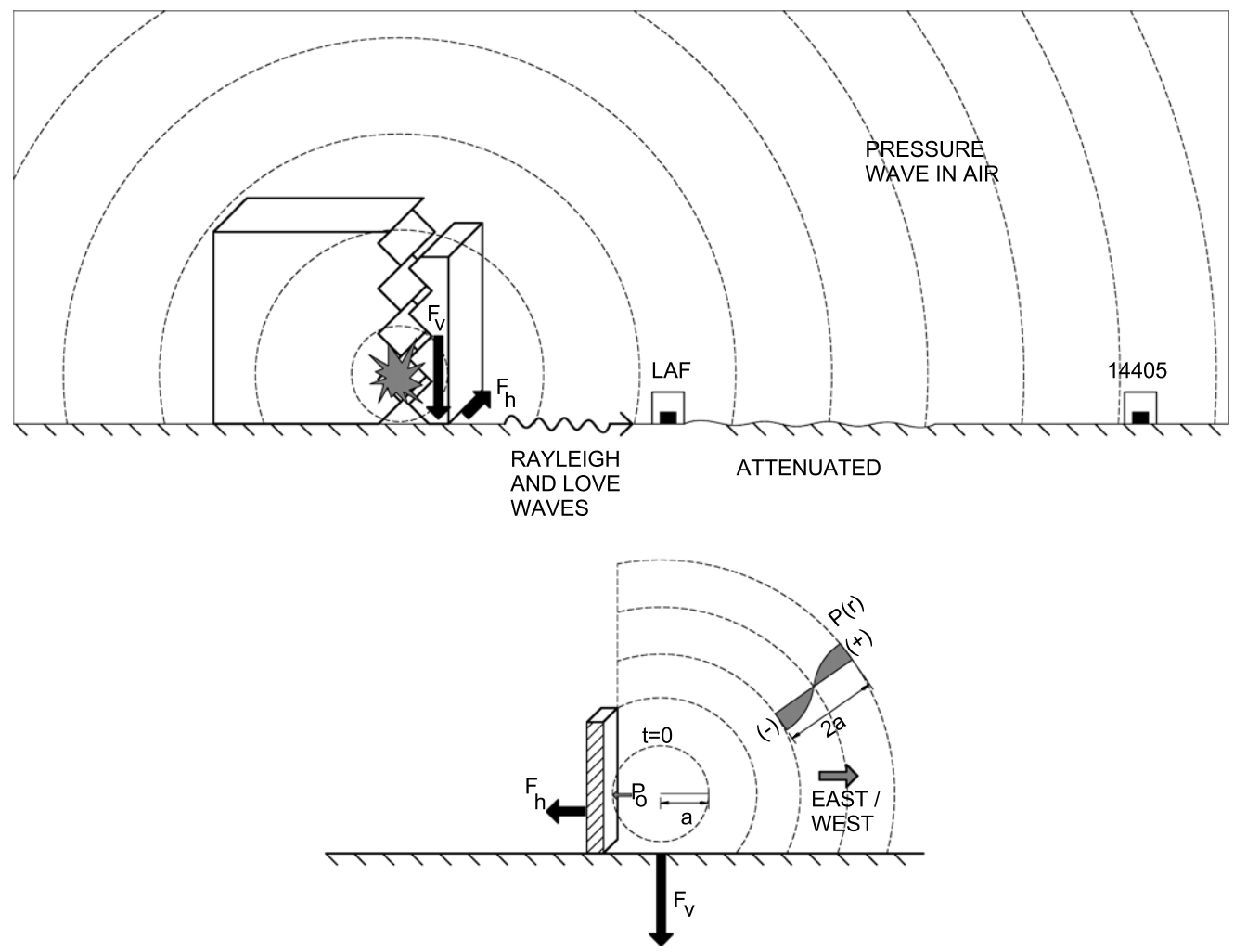

Figure 5. Schematic showing near-field features of explosion source. $F_{v}$ and $F_{h}$ : vertical and horizontal forces. a: radius associated with area on ground over which overpressure is applied. $\mathrm{P}_{o}$ : initial overpressure condition. LAF: SCSN broadband station LAF. 14405: SCSN strong-motion station 14405. T: time. P(r): pressure wave propagation as a function of distance $\mathrm{r}$. "+": compression. "-": rarefaction. Lengths are not to scale.

sediments (Table 1). The top $200 \mathrm{~m}$ of this seismic velocity structure is modeled after the Los Angeles Basin structure given in Magistrale et al. (2000; their figure 5). This velocity structure is similar to that derived specifically for the subsurface area near Torrance (Shaw et al. 2015). Figures $3 \mathrm{c}$ and $3 \mathrm{~d}$ show the ground-motion displacements computed for a single-force system consisting of a downward vertical force and a westward horizontal single force. Since we cannot determine the initial phase of the motion, we cannot determine the direction (west vs. east) of the horizontal force. If the observed waveform has a distinct beginning, it would be possible to determine the initial phase of the source function by removing the propagation phase delay. However, in our case it is difficult to do so because the ground noise obscured the beginning of the signal.

The time history of the force used for modeling is a box-car function with an amplitude of $10^{8} \mathrm{kN}$ and a duration of $\tau=0.1 \mathrm{~s}$. For this computation we used a frequency-wavenumber integration code developed by Herrmann (2013). The three-component waveforms computed for the Los Angeles basin seismic velocity structure (Figure 3c) matches the later portion of 
Table 1. Seismic velocity model. $H=$ depth; $\alpha=\mathrm{P}$-wave velocity; $\beta=$ shear-wave velocity; $\rho=$ density; $Q_{p}=$ P-wave attenuation; $Q_{s}=$ shear-wave attenuation.

\begin{tabular}{lccccr}
\hline \hline$H(\mathrm{~km})$ & $\alpha(\mathrm{km} / \mathrm{s})$ & $\beta(\mathrm{km} / \mathrm{s})$ & $\rho\left(\mathrm{g} / \mathrm{cm}^{3}\right)$ & $Q_{p}$ & $Q_{s}$ \\
\hline 0.03 & 1.2 & 0.4 & 1.80 & 100 & 25 \\
0.12 & 2.0 & 0.6 & 2.00 & 100 & 25 \\
0.85 & 2.5 & 1.0 & 2.20 & 100 & 25 \\
4.00 & 5.0 & 2.0 & 2.40 & 100 & 25 \\
5.00 & 5.5 & 3.18 & 2.50 & 1,000 & 250 \\
10.50 & 6.3 & 3.64 & 2.67 & 1,000 & 250 \\
15.00 & 6.7 & 3.87 & 2.80 & 1,000 & 250 \\
500.0 & 7.8 & 4.57 & 3.00 & 1,000 & 250 \\
\hline \hline
\end{tabular}

the observed waveforms (after $7 \mathrm{~s}$ on Figure 3a). Comparing the peak amplitude of the observed (Figure 3a) and synthetic displacements (Figure 3c), we estimate that the vertical force is approximately $2 \times 10^{5} \mathrm{kN}$. Comparison of the observed waveforms (Figure 3a) with the synthetic waveforms (Figure $3 \mathrm{c}$ ) also suggests a small initial pressure perturbation starting at about $2 \mathrm{~s}$ before the onset of the single force.

We estimate the approximate source duration from the frequency content of the observed signal. We computed waveforms for four source durations, $\tau=0.06,0.1,0.16$, and $0.2 \mathrm{~s}$, as shown in Figure 6. In general, as $\tau$ increases, the period of both Love and Rayleigh waves increases. When $\tau$ is $0.06 \mathrm{~s}$, a very high-frequency $\mathrm{P}$ wave is generated in the synthetic waveform as shown in Figure 6a. Such high-frequency energy is absent on the observed records. Comparison of the waveforms shown in Figure 6 and the observed waveforms shown in Figure $3 \mathrm{a}$ indicates that a duration of approximately $\tau=0.1 \mathrm{~s}$ is appropriate, though this estimate depends on the details of the time history.

The ground motion data best constrain the total force, and the estimate of the pressure depends on the area over which the force is applied. Since we assume that the force, $f$, responsible for the ground-level seismic excitation is due to the explosion overpressure, $P$, applied over a circular area on the ground with a radius $a, P$ can be estimated from $P=f /\left(\pi a^{2}\right)$ (Lamb 1960). For example, if $a=20 \mathrm{~m}$, then $P=160 \mathrm{kPa}$ (1.6 bar). These values depend on the details of the geometry and time history of the explosion, and cannot be resolved uniquely with data from only one seismic station.

Computing the total energy released is a complex problem that requires knowledge of the explosion source, the formation of the shock wave, and coupling between shock wave and motion of the building components. An approximate total acoustic wave energy can be estimated by considering an atmospheric wave propagating outward from the explosion source in a homogeneous atmosphere. We approximate the source as a spherical volume in which the pressure is applied. The radius of the sphere can be different from the radius of the circular area where the vertical force is applied, but for simplicity we use the same radius $a$ as an order of magnitude estimate of the source radius for the atmospheric wave excitation. Thus, our results are only valid within this simple approximation, but the overall effect is controlled by 


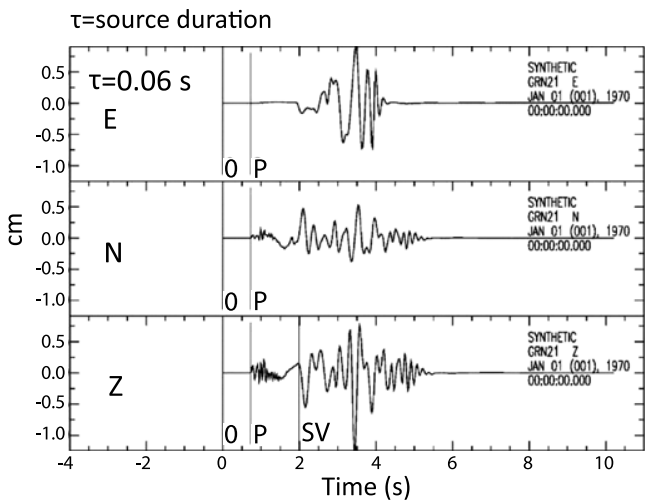

(a)

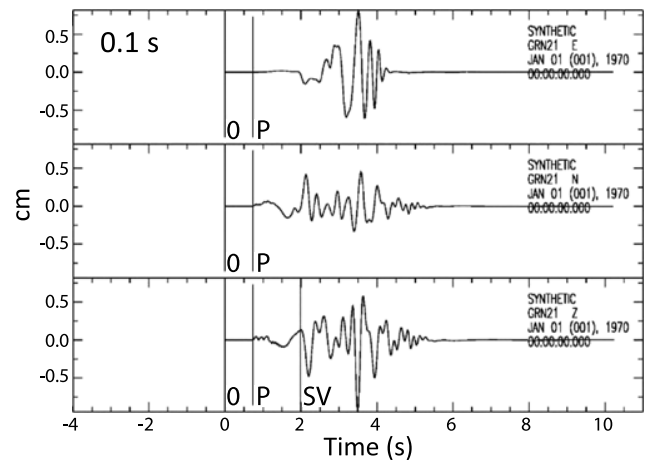

(b)

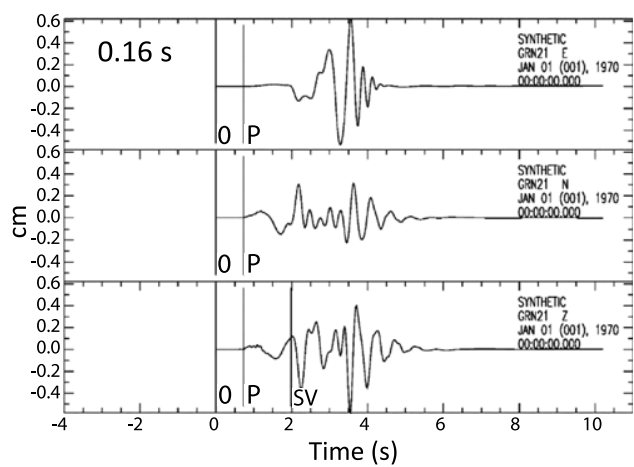

(c)

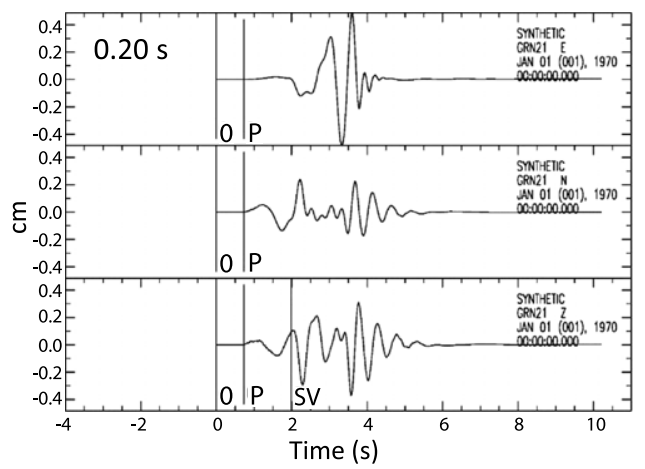

(d)

Figure 6. (a) Synthetic seismograms computed for box car force functions with variable duration, $\tau$. (a) $\tau=0.06 \mathrm{~s}$ with an amplitude of $1.7 \times 10^{8} \mathrm{kN}$; (b) $\tau=0.1 \mathrm{~s}$ with an amplitude of $10^{8} \mathrm{kN}$; (c) $\tau=0.16 \mathrm{~s}$ with an amplitude of $6.3 \times 10^{7} \mathrm{kN}$; and (d) $\tau=0.2 \mathrm{~s}$ with an amplitude of $5 \times 10^{7} \mathrm{kN}$. Vertical lines marked "O," "P," and "SV" indicate times corresponding to explosion origin, P-wave arrival, and vertically polarized S-wave arrival, respectively.

the total force and its duration which we believe are constrained well. In this model, the resulting wavefield is given by a propagating spherical shell with a thickness $2 a$ with compression in the outer half and rarefaction in the inner half of the shell (Figure 5). The propagating energy flux can be computed from the particle velocity of air in the shell. After integration over the finite shell thickness and associated propagation time, we find a total energy of $5.9 \times 10^{6} \mathrm{~kJ}$ for $a=20 \mathrm{~m}$ for the refinery explosion pressure wave. The calculation uses density $=1.2 \mathrm{~kg} / \mathrm{m}^{3}$, wave speed $=340 \mathrm{~m} / \mathrm{s}$, and a peak overpressure at the surface of the spherical source $=160 \mathrm{kPa}$ based on the force constrained by the seismic source analysis. This estimate should be considered highly uncertain due to our limited knowledge of the mechanics of what actually happened at the source and lack of data directly from the source location.

Comparison of the synthetic waveforms computed for a half space (Figure 3d) with that computed for the Los Angeles basin seismic velocity structure (Figure 3c) indicates that the 
duration of the observed record is due to dispersion caused by the Los Angeles basin seismic velocity structure. The seismic velocity model used in the synthetic seismogram computations (Table 1) has a shear-wave speed of $\beta=0.4 \mathrm{~km} / \mathrm{s}$ in the uppermost $30-\mathrm{m}$ thick layer. To investigate how the synthetic waveforms depend on $\beta$, we computed synthetics with $\beta=0.3,0.35$, and $0.5 \mathrm{~km} / \mathrm{s}$. The results are shown in Figure 7 together with the case of $\beta=0.4 \mathrm{~km} / \mathrm{s}$. It is apparent that the synthetic waveforms for cases with $\beta=0.5 \mathrm{~km} / \mathrm{s}$ and $0.3 \mathrm{~km} / \mathrm{s}$ are too short and too long, respectively (Figures $7 \mathrm{a}, 7 \mathrm{~d}$ ). The cases with $\beta=$ 0.40 to $0.35 \mathrm{~km} / \mathrm{s}$ exhibit approximately the right response (Figures $7 \mathrm{~b}, 7 \mathrm{c}$ ). The subsurface sediment velocity with $\beta=0.35 \mathrm{~km} / \mathrm{s}$ is similar to the one derived specifically for the subsurface area near Torrance (Shaw et al. 2015).

Synthetic seismogram, LA basin structure, $\beta_{1}=\mathrm{S}$ velocity in the top layer

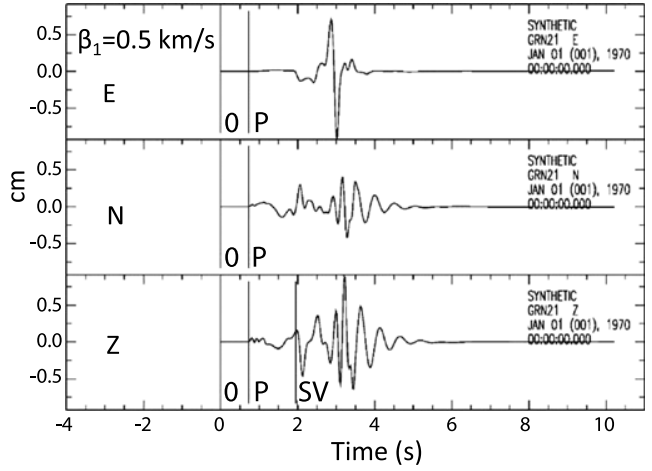

(a)

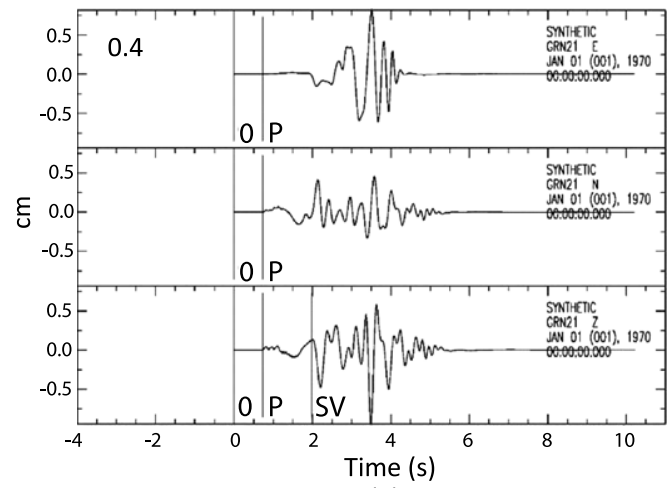

(b)

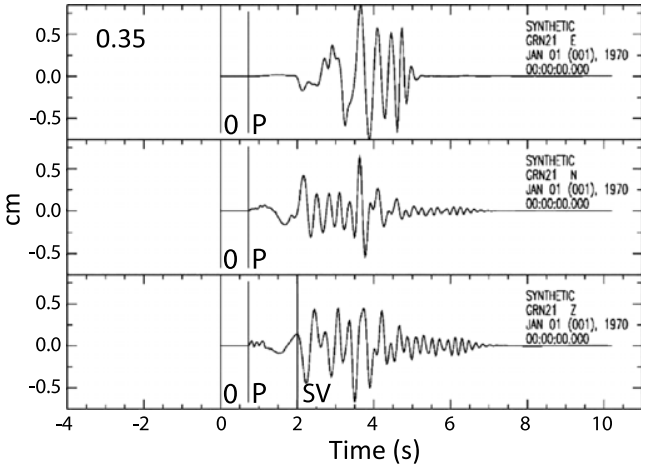

(c)

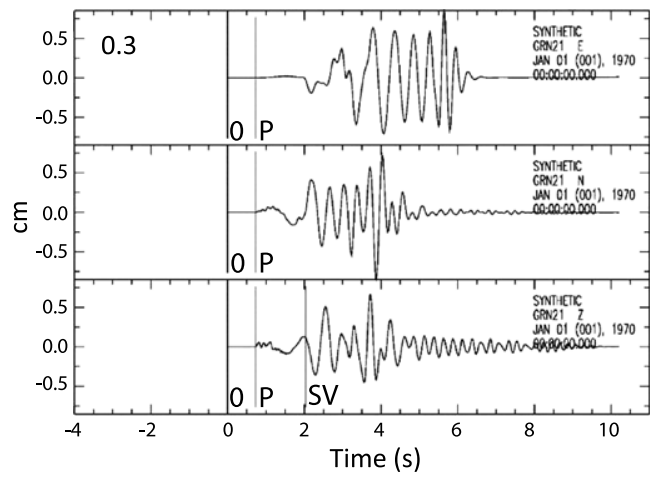

(d)

Figure 7. Synthetic seismograms computed for Los Angeles basin seismic velocity structure with shear-wave velocity $\beta$ in the top $30-\mathrm{m}$ thick layer equal to the following: (a) $0.5 \mathrm{~km} / \mathrm{s}$, (b) $0.40 \mathrm{~km} / \mathrm{s}$, (c) $0.35 \mathrm{~km} / \mathrm{s}$, and (d) $0.3 \mathrm{~km} / \mathrm{s}$. Vertical lines marked "O," "P," and "SV" indicate times corresponding to explosion origin, P-wave arrival, and vertically polarized S-wave arrival, respectively. 


\section{MODELING THE HIGH-RISE RESPONSE TO THE EXPLOSION}

In downtown Los Angeles, anomalous acceleration energy pulses were also recorded in a 52 -story high-rise building at a distance of $22.8 \mathrm{~km}$ from the explosion (Figures 1, 2). The arrival time of the coherent energy is $\sim 66 \mathrm{~s}$ after the explosion time, resulting in an estimated average source-receiver speed of $343 \mathrm{~m} / \mathrm{s}$; this corresponds closely to the average speed of a pressure wave in air. The signal-to-noise ratios of the anomalous pulses are dramatically improved with the application of a bandpass Butterworth digital filter with cut-off frequencies of $0.8 \mathrm{~Hz}$ and $2.0 \mathrm{~Hz}$. The accelerometer sensors in the 52-story high-rise are part of the CSN, a strong-motion network that currently consists of 800 stations located in the Los Angeles, California area (Clayton et al. 2011, 2015; Olson et al. 2011; Faulkner et al. 2011, 2014). The sensors in the network are low-cost MEMS accelerometers (Phidgets; phidget.com) that are capable of recording up to $\pm 2 \mathrm{~g}$ accelerations on-scale with a sensitivity of $\sim 70$ micro-g. The primary product of the CSN network is measurements of shaking of the ground level and upper floors in buildings in the seconds during and following a major earthquake. In addition to free-field stations, several buildings are instrumented with between three and 54 sensors (Kohler et al. 2013, 2014). The 52-story high-rise in downtown Los Angeles that recorded the refinery pressure wave discussed here has 54 sensors, one per floor on nearly every floor including basement levels. Spectra were obtained by computing the FFTs of the two-minute acceleration time series containing ambient vibrations and the pressure wave signal, after removing individual means and trends from each recording but before filtering (Figure 8). The spectra of the combined ambient vibrations and pressure wave signal during this time period show that the lowest frequencies of building vibration were not excited. Velocities and displacements were also examined by double integrating and filtering the acceleration time series. Except for the slightly lower frequency content as expected from integration, the time series look similar to acceleration.

Each CSN sensor uses a small, dedicated, single-board computer with enough processor power to analyze the sensor data in real time at 250 samples per second. Currently the CSN software running on the processor decimates the sensor data to $50 \mathrm{sps}$ for permanent archival. The software client maintains time synchronization with an accuracy of 20-50 milliseconds by use of the Network Time Protocol (NTP) infrastructure. This enables measurements of inter-floor wave propagation from earthquakes or other events such as wind gusts and explosions. CSN uses a cloud-based processing system that dynamically adjusts its size during an earthquake to handle the increased data load from the sensors. In CSN, the basic detection and feature measurements are carried out by the sensor system itself and the results are sent immediately to the CSN software running in Google's App Engine Cloud. This architecture increases the robustness of the system during a significant event.

What is unusual about these observations is the spatial and temporal density of sampling. It is widely recognized that one of the most effective ways to carry out high spatial resolution (on a scale of a few meters) monitoring of material property changes in structures (e.g., loss of stiffness due to damage) is to carry out dense sensor monitoring. Most buildings are not monitored by any vibration sensors, and the few that are have sparse sensing spatially, and infrequent sensing temporally. Usually only the strongest-motion earthquakes are recorded for short durations (few minutes), precluding the possibility of using lowamplitude ambient or small-magnitude earthquake vibrations to continuously monitor the 


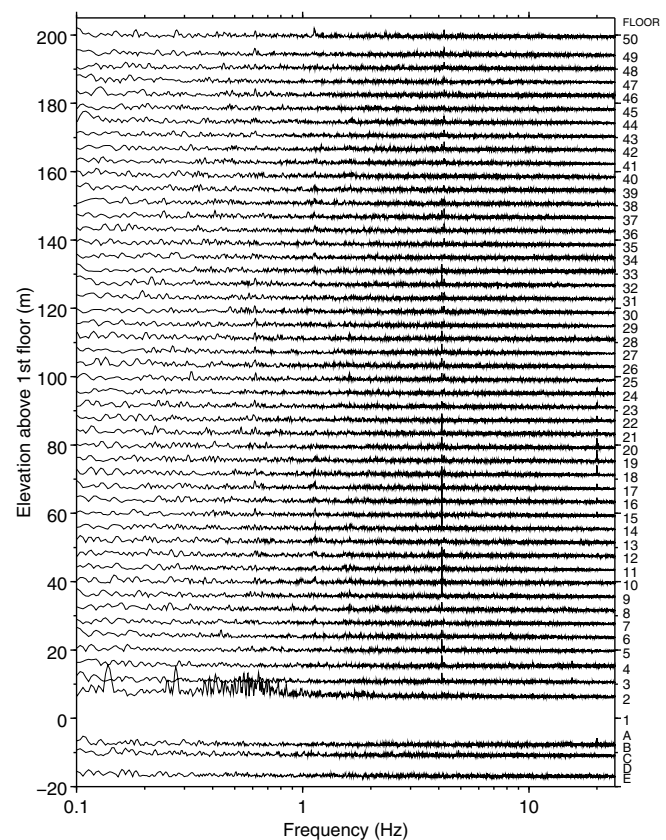

(a)

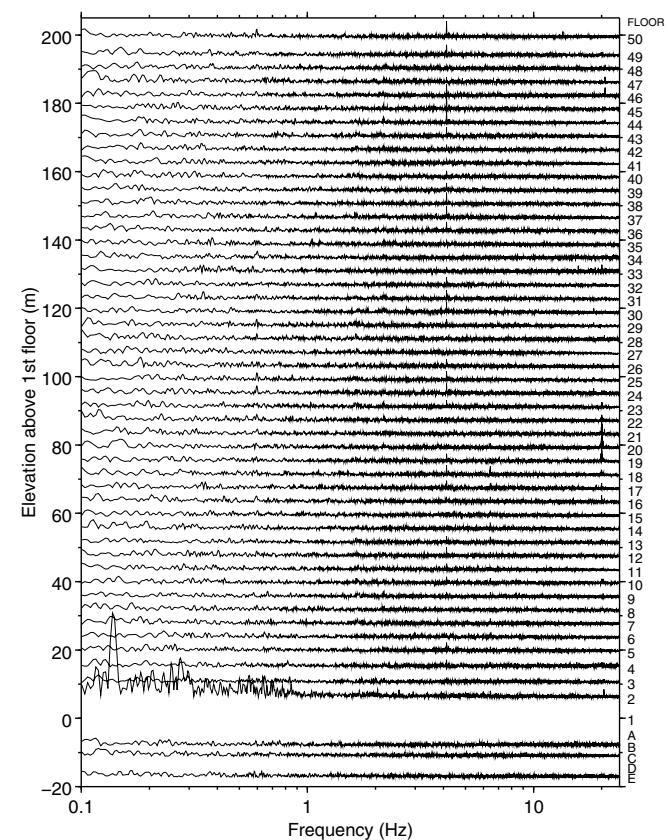

(b)

Figure 8. Fourier spectra [(a) north-south component, (b) east-west component] from the twominute acceleration time series recorded in a 52-story building in downtown Los Angeles after removing individual means and trends. Spectral amplitudes are normalized by a constant $(2,000 \mathrm{~m} \cdot \mathrm{s} / \mathrm{g})$ in order to show amplitudes as a function of floor height (in meters), and to show relative floor-to-floor amplitudes.

state-of-health of the structure, in addition to the state-of-health of the sensor network itself. The CSN has overcome long-standing problems associated with continuous dense monitoring by taking advantage of community volunteers to provide locations, security, power, and internet access for the CSN sensors.

The buildings instrumented by CSN are located in the greater Los Angeles area and include low-rise and high-rise office buildings, laboratory and dormitory buildings on university campuses, NASA's Jet Propulsion Laboratory; primary and secondary school campuses; and private residences (houses, apartment buildings, and condominiums). Here we focus on one of those buildings: a 52-story ( +5 basement levels) dual system office building located in downtown Los Angeles. This building's lateral system consists of a braced frame core surrounded by a steel moment frame. The floor plans contain various set-backs and notches along the building's vertical profile. The building was constructed in 1988 and is used exclusively as an office building. The structural system consists of three major components: an interior concentrically braced core, outrigger beams spanning approximately $12 \mathrm{~m}$ from the core to the building perimeter, and eight exterior outrigger columns. The beams perform three primary functions. They support gravity loads, act as ductile moment-resisting beams between the core and exterior frame columns, and enhance the 
overturning resistance of the building by engaging the perimeter columns to the core columns (Taranath 1997).

Using the acceleration responses recorded by the CSN array over the height of a building due to the refinery explosion, we calculated the absolute forces applied at each floor as a result of the atmospheric pressure wave. A pressure perturbation value is then obtained from the forces calculated for each floor to (1) illustrate what a co-located, high-sample rate barometer might have recorded, (2) compare with pressure perturbations expected for different levels of wind speed excitation, and (3) qualitatively evaluate different scenario pressure fields with different types and levels of structural damage. The calculations are carried out with the aid of a finite-element model of the building (Figure 9) which was developed

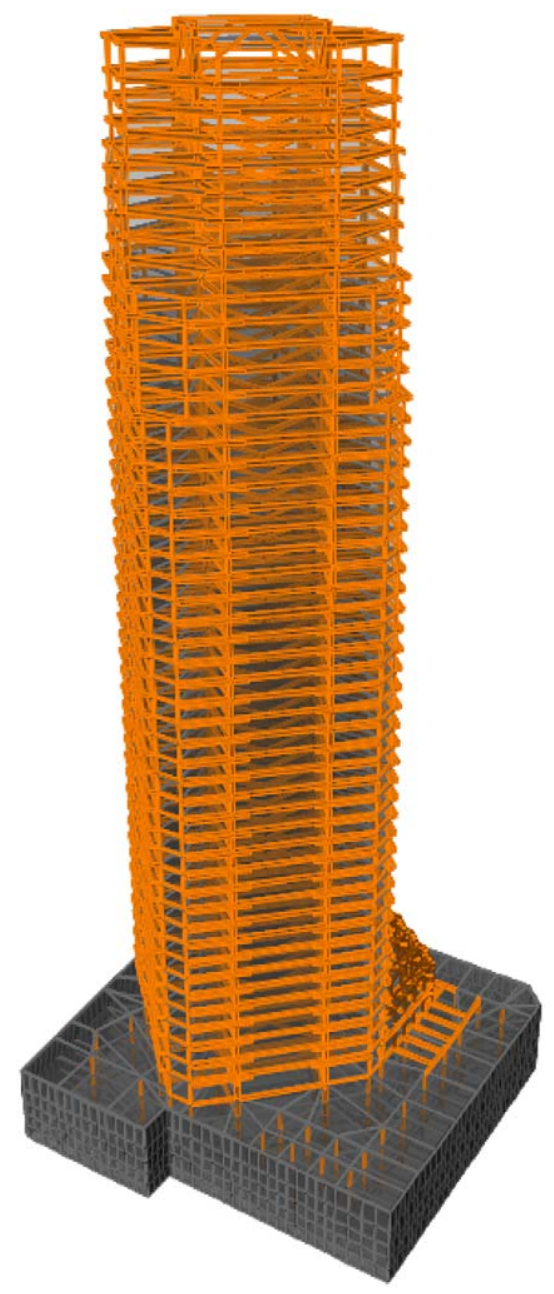

Figure 9. Finite-element ETABS model of 52-story building based on information about structural and connection elements obtained from structural engineering drawings. 
based on detailed information obtained from a complete set of structural drawings provided by the building owner. The major structural and connection elements obtained from the drawings are modeled using object-based physical-member modeling, such as built-in steel sections and braces (ETABS, Computers and Structures, Inc.), to represent each component's effective level of stiffness and mass. The finite-element software allows for static and dynamic linear simulations, as well as nonlinear analysis through insertion of nonlinear elements at locations of interest. Here we focus on linear elastic dynamics for the recorded pressure wave induced accelerations. The model has previously been calibrated by comparing recorded data from the building with simulated building response in the linear regime. Additional verification of the model was made in the frequency domain (matching modal frequencies and shapes), as well as in the time domain (shear-wave velocities and amplitudes of traveling waves).

In addition to the refinery explosion pressure wave data, the 4 January $2015 \mathrm{M}_{\mathrm{L}} 4.2$ Castaic Lake, California, earthquake at a distance of $71.5 \mathrm{~km}$ was recorded on nearly every floor of the 52-story building. Those waveforms, shown in Figure 10, are typical of the high-fidelity vibration data recorded by the dense CSN arrays in structures. The largest

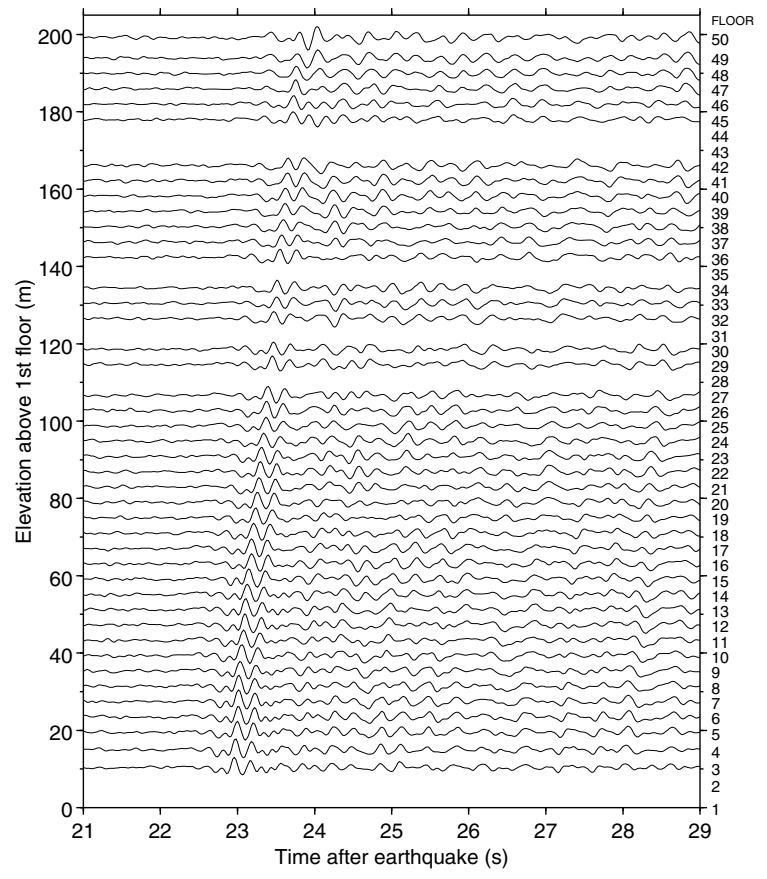

Figure 10. The 52-story building acceleration responses in the east-west direction to the 4 January $2015 \mathrm{M}_{\mathrm{L}} 4.2$ Castaic Lake, CA, earthquake (distance $=71.5 \mathrm{~km}$ ). Acceleration time series amplitudes are normalized by a constant $(1,500 \mathrm{~m} / \mathrm{g})$ in order to show amplitudes as a function of floor height (in meters), and to show relative floor-to-floor amplitudes. Floors for which data are not shown either had no installed sensor or had a faulty sensor recording at the time of the earthquake. 
absolute acceleration amplitude due to the Castaic Lake earthquake was $0.2 \% \mathrm{~g}$ and occurred on the $50^{\text {th }}$ floor recorded in the building east-west direction. Maximum relative displacement was $0.5 \mathrm{~mm}$ on multiple floors, after application of numerical double integration and a broadband filter. The vertical propagation speed of these waves agrees closely with transfer functions obtained when 24 hours of ambient vibration data are cross-correlated with the bottom floor - that is, using an interferometric method that is mathematically equivalent to deconvolving a "virtual" source waveform from every other station (Prieto et al. 2010; Clayton et al. 2015). Additional local earthquakes since then, for example the 30 April $2015 \mathrm{M}_{\mathrm{L}} 3.4$ Carson, California, and 3 May $2015 \mathrm{M}_{\mathrm{L}} 3.8$ Baldwin Hills, California, have been recorded in the building with similar quality.

On 18 February 2015, acceleration time series were recorded on nearly every floor of the 52 -story building in response to the explosion pressure wave (Figure 2). The maximum absolute accelerations recorded were $0.02 \% \mathrm{~g}$ and the maximum relative displacement was $0.03 \mathrm{~mm}$, computed after applying a passband Butterworth filter. The acceleration values for every floor shown in Figure 2 were normalized by the same constant, $13,000 \mathrm{~m} / \mathrm{g}$, in order to show the time series amplitudes relative to floor height in meters (shown on the vertical axes of Figure 2), and in order to show comparable relative amplitudes. We determined the pressure distribution over the height of the structure based on mass and stiffness distributions obtained from the finite-element model constructed specifically for this building. The equation of free vibration for the building system is:

$$
\boldsymbol{m} \ddot{u}(t)+\boldsymbol{c} \dot{u}(t)+\boldsymbol{k} u(t)=P(t)
$$

where $\boldsymbol{m}$ is the mass matrix, $\boldsymbol{c}$ is the damping matrix, $\boldsymbol{k}$ is the stiffness matrix of the building model, $\ddot{u}(t), \dot{u}(t)$, and $u(t)$ are acceleration, velocity, and displacement responses as a function of time $t$, and $P(t)$ are the applied forces. The finite-element model accurately produces the free vibration characteristics (modal shapes and frequencies) when compared with recorded ambient vibration acceleration data; thus we believe the mass and stiffness matrices in Equation 1 to be well constrained for the 52-story building. Further, when compared with moderate size earthquake data, the overall response of the building compares closely with the measured response from the in situ sensors.

In order to invert for the input force values, the stiffness, mass, and damping matrices of the building first needed to be reconstructed so that the spatial resolution of the model matched that provided by the sensor sampling. The observed accelerations are recorded on a floor-by-floor spatial scale, whereas the full finite-element building model contains many more degrees of freedom including those associated with all local intersections (connections) of elements at every floor, and at intermittent (inter-floor) levels. This creates an underdetermined problem since the spatial scale of the sampling precludes the determination of all (monitored and unmonitored) degrees of freedom directly. To overcome this, we performed direct static condensation of the structural model in order to develop a reduced system which takes into account the larger system's full stiffness and mass proportions.

In dynamic systems such as buildings, there are many degrees of freedom which are not directly associated with mass. To develop the reduced system, all massless degrees of freedom (e.g., tips of columns, connection elements) are condensed from the system. Since the arrays of sensors are located one per floor, we lump masses at each floor level (Figure 11a) in 


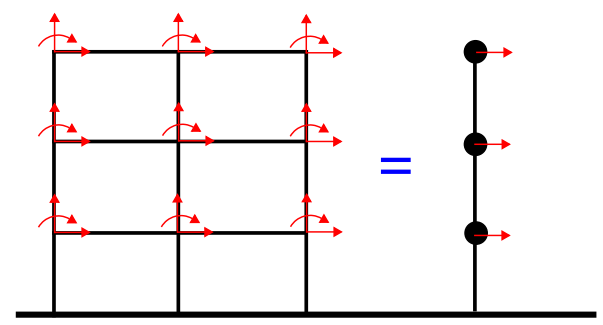

(a)

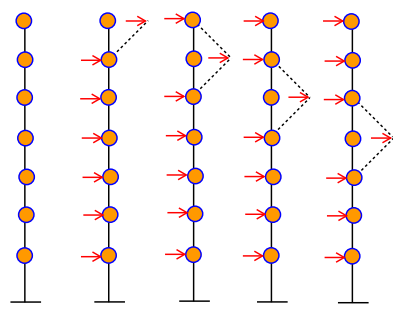

(b)

Figure 11. (a) Schematic illustrating how building model is condensed to a form in which masses are lumped at each floor in order to match the observational degrees of freedom. (b) Schematic illustrating "pop and lock" method in which a load is applied to the center of mass of each floor, one at a time. The resulting displacement and restraining forces are determined in order to obtain the stiffness matrix elements in condensed form.

order to have a direct measurement of inertial forces. This accounts for all the mass in a smaller, reduced degree-of-freedom system for which all displacements, velocities, and accelerations are known from the observations. A simple manipulation of the stiffness matrix is performed to reduce the problem to only the degrees of freedom associated with the lumped masses. The undamped dynamic equations of motion, with forces applied only to the inertial degrees of freedom, can be expressed as:

$$
\left[\begin{array}{cc}
\boldsymbol{m}_{t t} & \mathbf{0} \\
\mathbf{0} & \mathbf{0}
\end{array}\right]\left\{\begin{array}{l}
\ddot{u}_{t} \\
\ddot{u}_{0}
\end{array}\right\}+\left[\begin{array}{ll}
\boldsymbol{k}_{t t} & \boldsymbol{k}_{t 0} \\
\boldsymbol{k}_{0 t} & \boldsymbol{k}_{00}
\end{array}\right]\left\{\begin{array}{l}
u_{t} \\
u_{0}
\end{array}\right\}=\left\{\begin{array}{c}
p_{t}(t) \\
0
\end{array}\right\}
$$

where subscript " 0 " degrees of freedom are massless, and subscript " $t$ " degrees of freedom represent the transformed reduced problem (Chopra, 2012). Following the derivation in Chopra (2012), the partitioned equations are:

$$
\boldsymbol{m}_{t t} \ddot{u}_{t}+\boldsymbol{k}_{t t} u_{t}+\boldsymbol{k}_{t 0} u_{0}=p(t) \boldsymbol{k}_{0 t} u_{t}+\boldsymbol{k}_{00} u_{0}=0
$$

and since there is no inertial term associated with the massless degrees of freedom, the displacements, $u_{0}$, can be substituted into the initial partitioned equation displacements:

$$
\boldsymbol{m}_{t t} \ddot{u}_{t}+\boldsymbol{k}_{t t} u_{t}-\boldsymbol{k}_{0 t}^{T} \boldsymbol{k}_{00}^{-1} \boldsymbol{k}_{0 t} u_{t}=\boldsymbol{m}_{t t} \ddot{u}_{t}+\hat{\boldsymbol{k}}_{t t} u_{t}=p_{t}(t)
$$

to produce the condensed stiffness matrix:

$$
\hat{\boldsymbol{k}}_{t t}=\boldsymbol{k}_{t t}-\boldsymbol{k}_{0 t}^{T} \boldsymbol{k}_{00}^{-1} \boldsymbol{k}_{0 t}
$$

(Chopra 2012). This reduced order matrix is only based on the stiffness of the structure and is independent of the mass distribution. Instead of solving the full problem numerically, we achieve the same solution by instituting a numerical, iterative method described next which uses static analysis of the system to determine the appropriate values of this matrix. The result is that the dynamic calculation is no longer directly dependent on the inertial terms. 
To construct the reduced degree-of-freedom model, we developed reduced-order stiffness and mass matrices. Since mass distribution over the height of the building is well known from validation of the ETABS model results to the measured responses, assembling a reduced order mass matrix with lumped floor level quantities was straightforward. Because excitation accelerations are small and there are no additional sensors on each floor to measure rotational motion, torsion is not included in this study.

Developing the reduced system of equations corresponding to the observational degrees of freedom is accomplished by performing a classical "pop and lock" method to condense the stiffness matrix. To determine the values of the condensed stiffness matrix elements, a large static load, $F_{n}$, (between $4.4 \times 10^{4} \mathrm{kN}$ and $4.4 \times 10^{5} \mathrm{kN} ; 10,000$ and $100,000 \mathrm{kips}$ ) is applied to the center of mass of each floor, one at a time. The loads are applied to a model in which all associated center-of-mass degrees of freedom are initially prevented from directly translating. We then "unlock" each degree of freedom, one at a time, and compute the displacement $u_{n}$ at that released degree of freedom, $n$, through the linear elastic lateral resistance relation:

$$
k u_{n}=F_{n}
$$

as well as the magnitude of the forces necessary to restrain all other floors from displacing. We normalize each set of forces by dividing by the displacement at the unlocked degree of freedom to populate the $N \times 1$ stiffness matrix $k_{l, n}(l=1, N)$ :

$$
k_{l, n}=\left(\begin{array}{c}
k_{1, n} \\
\vdots \\
k_{(n-1), n} \\
k_{n, n} \\
k_{(n+1), n} \\
\vdots \\
k_{(N), n}
\end{array}\right)
$$

associated with floor $n$ where the individual load is applied. Figure $11 \mathrm{~b}$ illustrates this process schematically. By assembling sequentially each $k_{l, n}$, we construct the global stiffness matrix $K$ in its condensed form:

$$
\boldsymbol{K}=\left(\begin{array}{ccccc}
k_{1,1} & \cdots & k_{1, n} & & k_{1, N} \\
& \ddots & \vdots & & \\
& & k_{(n-1), n} & & \\
\vdots & & k_{n, n} & & \vdots \\
& & k_{(n+1), n} & & \\
& & \vdots & \ddots & \\
k_{N, 1} & & k_{(N), n} & \cdots & k_{N, N}
\end{array}\right)
$$


To ensure exact symmetry of the stiffness matrix for numerical purposes, we take the average values of all off-diagonal symmetric elements and repopulate the off-diagonal terms. The eigenvectors and frequencies of the condensed form are compared with the full ETABS model and are found to be in good agreement, indicating that the condensation matrices have been successfully assembled.

The analytical ETABS model was originally developed without rigid diaphragms, an assumption which allowed for flexibility of the floors in plane. To perform static condensation, a rigid diaphragm is needed to ensure that all masses moved together. This changed the modal properties by increasing the stiffness, corresponding to an approximately $5 \%$ decrease in period. Table 2 shows a comparison of the two ETABS models (with and without the rigid diaphragm assumption) compared to the reduced model which assumed rigid diaphragms. We show all models to demonstrate that there is a small difference, mainly due to the rigid body assumption associated with the floor, but that this difference has a very small effect on the results. The reduced model comes from the rigid diaphragm model static condensation. Figure 12 shows the mode shapes associated with each mode.

With the reduced stiffness and mass matrices, we then reconstruct a damping matrix with the assumption of Rayleigh damping, $\boldsymbol{c}=a_{0} \boldsymbol{m}+a_{1} \boldsymbol{k}$. To construct the damping matrix, we use coefficients $a_{0}$ and $a_{1}$, such that damping coefficients for the first and fourth modes are fixed at $1 \%$. We use Rayleigh damping for simplicity; however any physically appropriate damping scheme can be straightforwardly implemented with this approach.

Once the components of the stiffness, damping, and mass matrices are determined, the time-varying force function (right hand side of Equation 1) is calculated using the acceleration time histories, that is, the recorded accelerations, measured at every floor. Theoretically, this force should be zero up until the time when the pressure wave reaches the structure. Instrument and environmental noise are lower in amplitude than the pressure wave response, but they introduce error in the forcing function calculations. To reduce a portion of this error, a spatial filter using the first five translational eigenmodes in the north-south direction of the structural system is applied to the acceleration, velocity and displacement time series

Table 2. Comparison of first five translational periods for the 52-story building in the east-west and north-south directions from the ETABS model without rigid diaphragms, ETABS model with rigid diaphragms, Reduced Order Model described in text, and Observed.

\begin{tabular}{|c|c|c|c|c|c|c|c|c|}
\hline \multirow[b]{2}{*}{ Mode } & \multicolumn{4}{|c|}{ East-west period (s) } & \multicolumn{4}{|c|}{ North-south period (s) } \\
\hline & $\begin{array}{c}\text { ETABS } \\
\text { without rigid } \\
\text { diaphragms }\end{array}$ & $\begin{array}{c}\text { ETABS } \\
\text { with rigid } \\
\text { diaphragms }\end{array}$ & $\begin{array}{c}\text { Reduced } \\
\text { Order } \\
\text { Model }\end{array}$ & Observed & $\begin{array}{c}\text { ETABS } \\
\text { without rigid } \\
\text { diaphragms }\end{array}$ & $\begin{array}{c}\text { ETABS } \\
\text { with rigid } \\
\text { diaphragms }\end{array}$ & $\begin{array}{l}\text { Reduced } \\
\text { Order } \\
\text { Model }\end{array}$ & Observed \\
\hline 1 & 6.023 & 5.903 & 5.903 & 5.700 & 5.699 & 5.574 & 5.572 & 5.380 \\
\hline 2 & 1.745 & 1.673 & 1.673 & 1.648 & 1.717 & 1.642 & 1.642 & 1.640 \\
\hline 3 & 0.915 & 0.872 & 0.871 & 0.846 & 0.951 & 0.909 & 0.908 & 0.894 \\
\hline 4 & 0.629 & 0.597 & 0.598 & 0.600 & 0.708 & 0.686 & 0.684 & 0.616 \\
\hline 5 & 0.494 & 0.471 & 0.471 & 0.450 & 0.591 & 0.564 & 0.563 & 0.465 \\
\hline
\end{tabular}



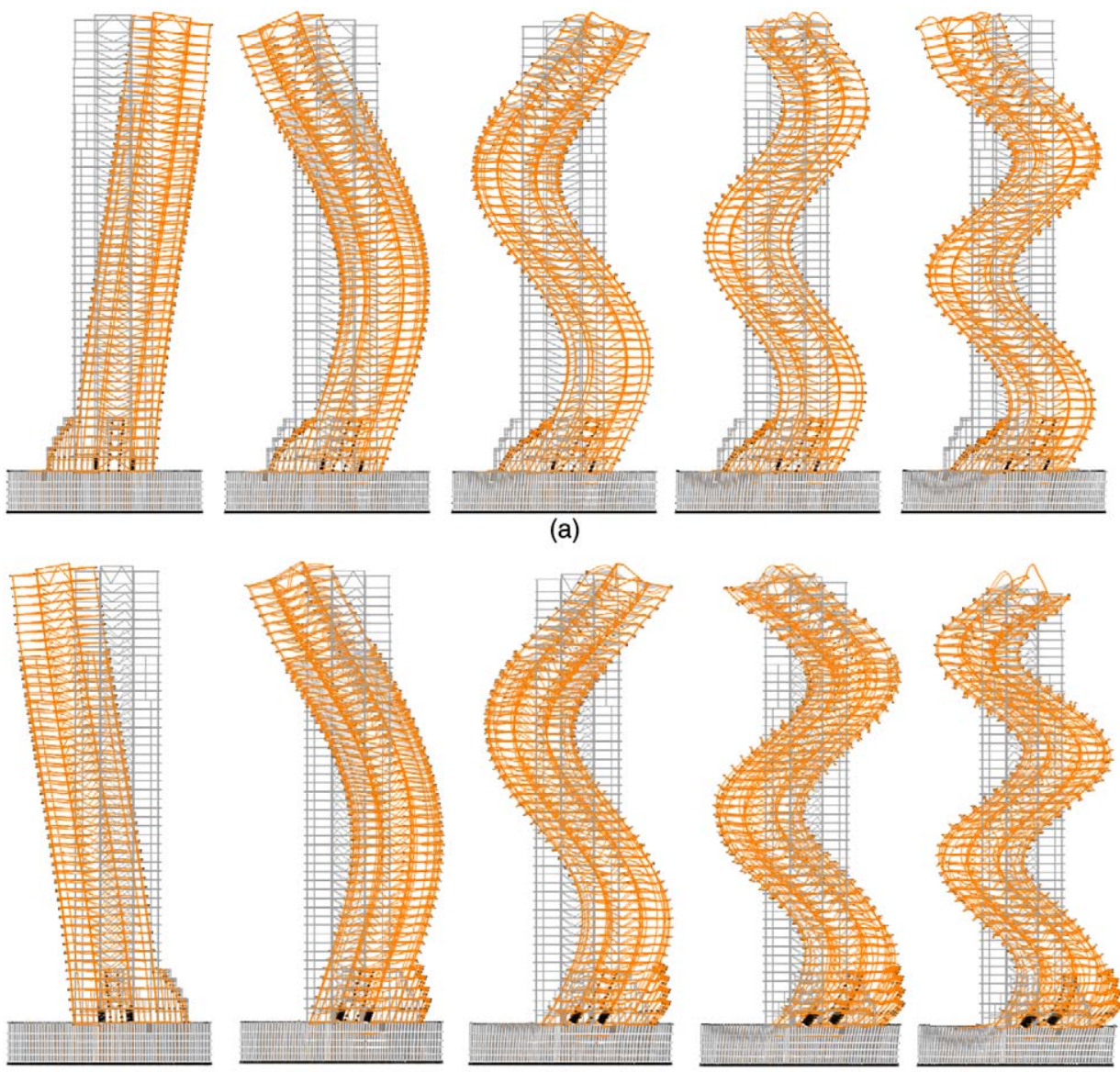

(b)

Figure 12. Mode shapes associated with the first five translational modes in the (a) north-south and (b) east-west directions.

(Figure 13). This aids in minimizing inaccuracies associated with timing errors as well as noise. The resulting displacement time series constructed with modal summation (Figure 13) was used in the computation of the resisting force (Equation 6). Figure 13 shows a snapshot in time of the relative displacement in the north-south direction over the height of the building, and illustrates the results of the application of a spatial filter using modal reconstruction. The eigenfrequencies associated with these first five translational modes are shown in Table 2. The first five modes correspond to the frequency content of the observed signal. The spatial filter function consists of modal summation with appropriate boundary conditions to fit the time series values over the building height, with a separate filter found for each simultaneous time point. The application of the spatial filter smooths the data so that small errors, not associated with the pressure signal, will not result in large errors in estimates for the forcing function through the lateral resistance term in Equation 1. Note that although Figure 13 is a particular snapshot in time of relative displacements and shows a predominance 


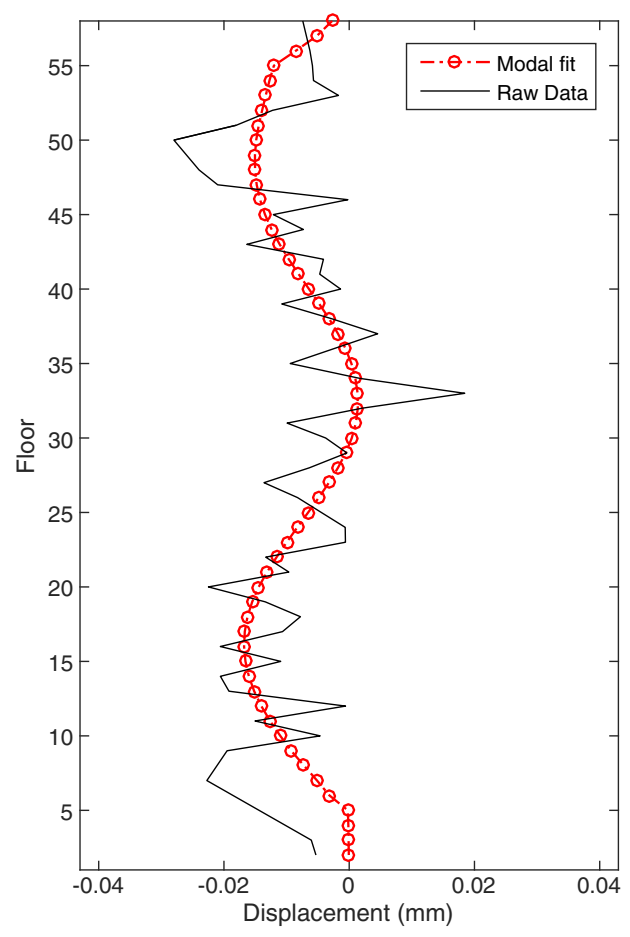

Figure 13. Relative displacements in the north-south direction over the height of the building at an instantaneous time point in the recorded accelerations during the pressure wave excitation. Black curve: recorded observations. Red circles: smoothed approximation using the first five translational modes.

of higher mode contribution, the displacements at other times show different modal contributions. The total relative displacement is always the sum of the modal contributions of the first through fifth translational modes to best fit the data. After application of the spatial filter, we compute a force distribution for a range of upper floors with a maximum amplitude of $1.42 \mathrm{kN}$ (0.32 kips). Distributing this force over the height and width of a typical floor gives a maximum average pressure perturbation of $7.7 \mathrm{~Pa}$.

Analogous calculations using the acceleration time series waveforms recorded in the building's east-west direction were performed. The eigenfrequencies associated with the first five translational modes in the east-west direction are shown in Table 2. Using the same method as before, the maximum amplitude of the force was computed as $1.1 \mathrm{kN}$ (0.24 kips) which translates into an average pressure perturbation of 5.8 $\mathrm{Pa}$.

\section{DISCUSSION}

In the 52-story building in downtown Los Angeles, the pressure perturbation found from the explosion pressure wave can be converted to an equivalent wind speed, $V$, by means of the Bernoulli equation for dynamic pressure, $p$, and density, $\rho$ : 


$$
1 / 2 \rho V^{2}=p
$$

For standard atmospheric density:

$$
0.591 V_{\mathrm{m} / \mathrm{s}}^{2}=\mathrm{p}_{\mathrm{Pa}}
$$

resulting in a wind speed of $3.6 \mathrm{~m} / \mathrm{s}(8 \mathrm{mph})$. Closer examination of the anomalous energy pulses in Figure 2 shows that the wave does not arrive exactly at the same time on every floor. There is a time variation among different floors of approximately $1.5 \mathrm{~s}$ between the earliest and latest arrivals, which is much larger than errors associated with NTP time. The elastic response is different in the north-south direction than in the east-west direction. More specifically, in the north-south direction, the response appears to have the largest amplitude on floors 7-12, and 16-29, and to a lesser extent on floors 39-43. In the east-west direction the amplitudes are clearer on more floors. Here the response shows up clearly on floors 6-10, 15-19, 23-32, and 37-45. We hypothesize that this may be due to scattering of the pressure wave as it propagates northward over the Los Angeles basin and into the complex layout of closely-spaced buildings in downtown Los Angeles, as well as interaction with the irregular, external face geometry of the 52-story high-rise itself. Full understanding of the wave's path would ideally require a 3D model that includes variations in terrain elevation, all buildings with accurate spacing and geometries, and thermal variations.

To ensure that we had all possible recorded pressure data available for this study, we searched, and contacted, the NOAA National Weather Service (NWS) for high sample rate barometer data in the Los Angeles area but found that most barometers associated with weather stations record data at a rate of 1 sample/hour, with an exceptional few recording at 1 sample/5 minutes, neither of which is sufficient to verify the presence of a blast pressure wave in the basin.

To validate our observations and illustrate how a tall building might respond to pressure waves of different time durations and amplitudes, we use the full finite-element building model to compute the building's response to an external impulse of horizontal force applied simultaneously at every floor. Since we are simulating the response of the building to a plane wave of pressure, we scale the force impulse according to the projected cross-sectional area of the building as a function of height because the top of the building is narrower than the bottom. The computed response to the impulsive force time function is an impulse response function for a horizontal pressure plane wave. We can therefore obtain the response to any more complex horizontal force as a function of time, simultaneously at all heights, by convolving the force time function with our impulse response function.

We examine the 52-story building's simulated response in acceleration, velocity, displacement, force, and time-integrated force. We approximate the impulse input using an isosceles triangle function force time history with duration of $0.1 \mathrm{~s}$ applied to the center of each floor above the ground level. When the impulse is applied, the internal stiffness forces of the building are not directly engaged initially; thus the floors of the building increase their linear momentum as a function of the time integral of the forcing function. If the building is at rest when the pressure wave arrives, then the solution is identical to the problem of free vibrations of the building with an initial condition of no displacement, but with an initial velocity that is the integral of the impulsive force divided by the mass of the floor. 
Since the mass of the lower floors is much greater than that of the higher floors, we expect that the initial velocities will be correspondingly larger for the higher floors (despite the smaller forces that arise from the smaller cross-sectional area).

The linear-elastic dynamic response to scenario pressure wave input is calculated using ETABS, and noise is added to the solution to more closely match the signal-to-noise ratios in the data. The noise time series are obtained from actual ambient vibration noise recorded from each floor of the 52-story building on CSN sensors. A narrowband Butterworth filter is applied to the simulation results with cut-off frequencies equal to those applied to the explosion data $(0.8 \mathrm{~Hz}$ to $2.0 \mathrm{~Hz})$. We model the response in a fixed-base coordinate system.

The results of the computations before and after adding noise and filtering are shown in Figure 14 which illustrates the instantaneous acceleration pulse (i.e., the time derivative of the velocity that corresponds to a step change in momentum when the pressure pulse arrives), velocity, and displacement that occurs at the time of excitation (time $=6 \mathrm{~s}$ in Figure 14). Figure 14a shows simulations of acceleration, velocity, and displacement responses with no noise added, and after application of a very broadband Butterworth filter $(0.01 \mathrm{~Hz}$ to $20.0 \mathrm{~Hz}$ ). Figure 14a also illustrates what would be observed in sensitive, high dynamic range sensors in linear response to large-amplitude pressure excitation. Figure 14b shows analogous responses after application of a narrowband Butterworth filter $(0.8 \mathrm{~Hz}$ to $2.0 \mathrm{~Hz}$ ). Figure $14 \mathrm{c}$ shows responses with noise added and after application of the broadband filter $(0.01 \mathrm{~Hz}$ to $20.0 \mathrm{~Hz})$, and Figure $14 \mathrm{~d}$ shows analogous responses with noise added and after application of the narrowband filter. Figure 14e shows the Fourier spectra corresponding to Figure 14c. Figures $14 \mathrm{c}, 14 \mathrm{~d}, 14 \mathrm{e}$ were constructed to be comparable to our CSN data set.

The impulses in Figure 14 grow in amplitude up the building since the higher floors have less mass. The displacement plots show that the pressure pulse simultaneously imparts momentum to every floor. Since the building is fixed at the base, a wave propagates from the base of the building, and the building begins to oscillate primarily in its fundamental mode. Although this is the expected motion of the building, the accelerations from the wave are too small to be observed in our noisy records (Figures 2 and 14c, 14d). Unfortunately, we do not have any independent measure of the air pressure time history near our building, and it was likely different from the 0.1 -second isosceles triangle assumed in this simulation. Ideally, if we had detailed information about the explosion source characteristics and propagation effects of the pressure wave through the city, we would model the pressure input as a more realistic blast wave interacting with and reflecting off other nearby surfaces, and wrapping around other buildings. In a more physically realistic formulation, the initial shock wave front would be a function of the peak pressure at the source. The time duration of the positive and negative polarity components of the subsonic pressure wave would be a function of the total energy, and the propagation path and distance (Kinney 1962). While we are not able to fully model the lower frequency characteristics of the positive and negative pressure phases associated with the subsonic flow field, we are able to capture the initial impulsive character of the leading shock wave front.

Although this application is different from acceleration time functions applied at a building's base to simulate and validate building response to earthquakes (Kohler et al. 2007, Cheng et al. 2015), we see an analogous phenomenon in Figure 14. At all floor levels above the first floor which is fixed, we first observe the instantaneous force (pressure) 

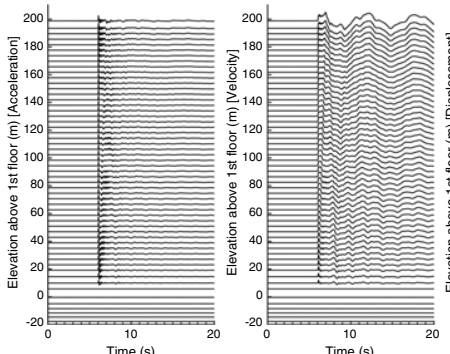

(a)

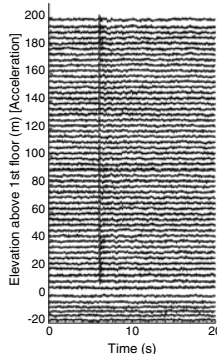

Time $(\mathrm{s})$

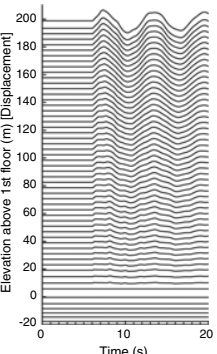

Time (s)

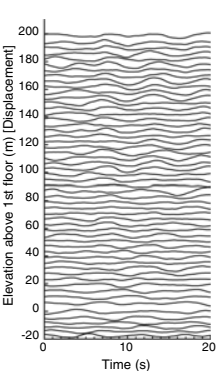

(c)
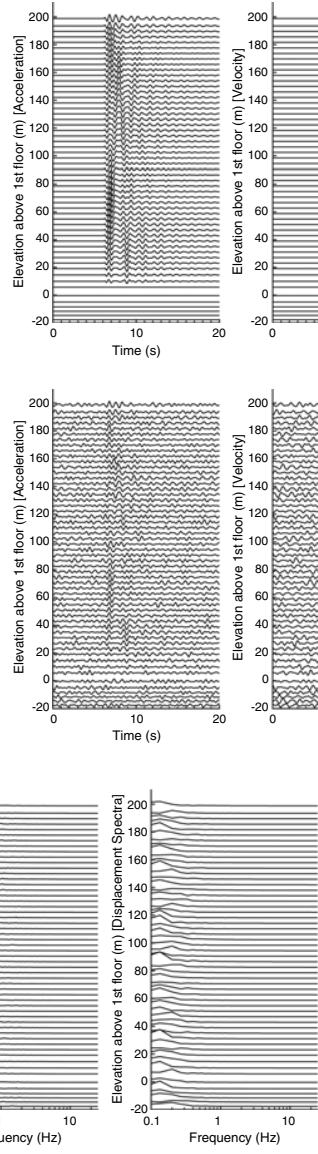

(d)

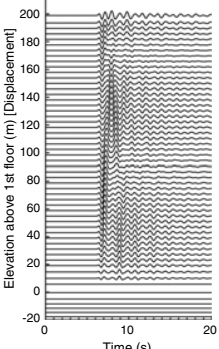

(b)
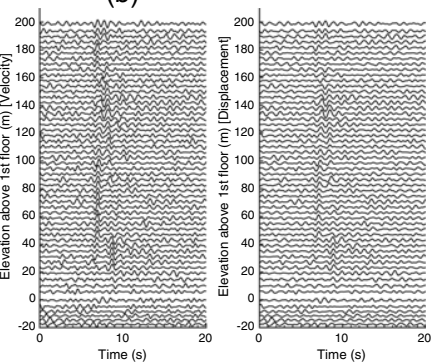

me (s)
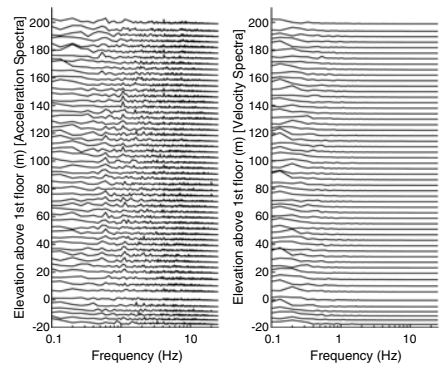

(e)

Figure 14. Simulated acceleration (left), velocity (middle), and displacement (right) responses of the 52-story building to a planar pressure wave input given by a triangle function with time duration of $0.1 \mathrm{~s}$ with: (a) no noise added and after application of broadband filter, (b) no noise added and after application of narrowband filter, (c) noise added and after application of broadband filter, (d) noise added and after application of narrowband filter, and (e) Fourier spectra of (c).

wave pulse, but next we observe the onset of a traveling wave comparable to that excited by earthquake motions (Kohler et al. 2007, Cheng et al. 2015). In this case, the traveling waves arise from interactions of the planar wave with the bottom fixed and top free boundary conditions, as well as with large stiffness and mass gradients between mid-level floors.

Pressure-induced accelerations associated with actual wind events in the Los Angeles basin are also being recorded by the CSN building arrays. A recent wind event in the Los Angeles basin caused sustained increases in acceleration response in the 52-story building that we used to independently validate the approach used to interpret the explosion response. On 24 March 2015, downtown Los Angeles experienced a modest wind storm 
with wind speeds fluctuating over a six-hour interval up to a maximum of $11.2 \mathrm{~m} / \mathrm{s}(25 \mathrm{mph})$ for gusts and up to $6.7 \mathrm{~m} / \mathrm{s}(15 \mathrm{mph}$ ) for sustained wind speeds (Wunderground 2015). The weather station from which these data were obtained is located approximately $1.1 \mathrm{~km}$ northeast of the building. This was the first moderately significant wind event since the array was installed, providing constraints for determining the demand on the structural system. Figure 15 shows the acceleration time series and corresponding spectra illustrating the predominance of first mode response, recorded in the north-south direction of the 52-story building during this wind event. The east-west accelerations and spectra look similar. Using the recorded acceleration time series (Figure 15a), we resolved floor-by-floor forces in a similar manner to what was calculated for the refinery explosion pressure wave. Over the course of 30 minutes during which the wind speeds were the largest, we calculated a maximum floor force of $6.0 \mathrm{kN}$ (1.34 kips) from the acceleration data. This corresponds to a wind-induced pressure perturbation of $31.6 \mathrm{~Pa}$. This pressure perturbation is consistent with a $7.2 \mathrm{~m} / \mathrm{s}$ (16 mph) wind speed computed using the same method as before. In this case however, because the building responded to wind excitation almost exclusively in its first eigenmode, only the first translational eigenfrequency was required for constructing the spatial filter (Figure 16).

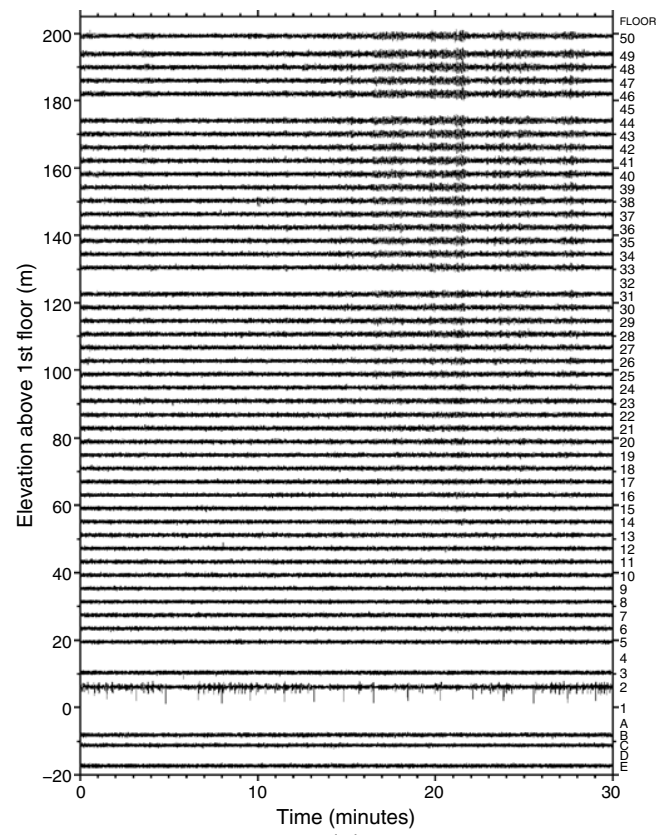

(a)

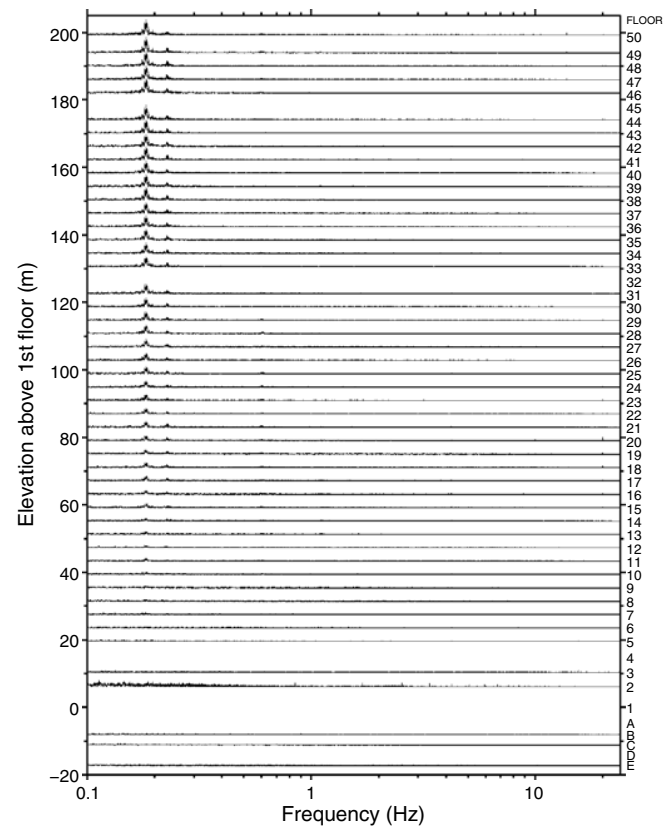

(b)

Figure 15. Accelerations (a) and spectra (b) from north-south response of 52-story building during the 24 March 2015 strong wind event. Acceleration time series amplitudes are normalized by a constant $(3,000 \mathrm{~m} / \mathrm{g})$, and spectral amplitudes are normalized by a constant $(80 \mathrm{~m} \cdot \mathrm{s} / \mathrm{g})$ in order to show values as a function of floor height (in meters) and relative floor-to-floor values. East-west records look similar. Floors for which data are not shown either had no installed sensor or had a faulty sensor recording at the time of the wind event. 


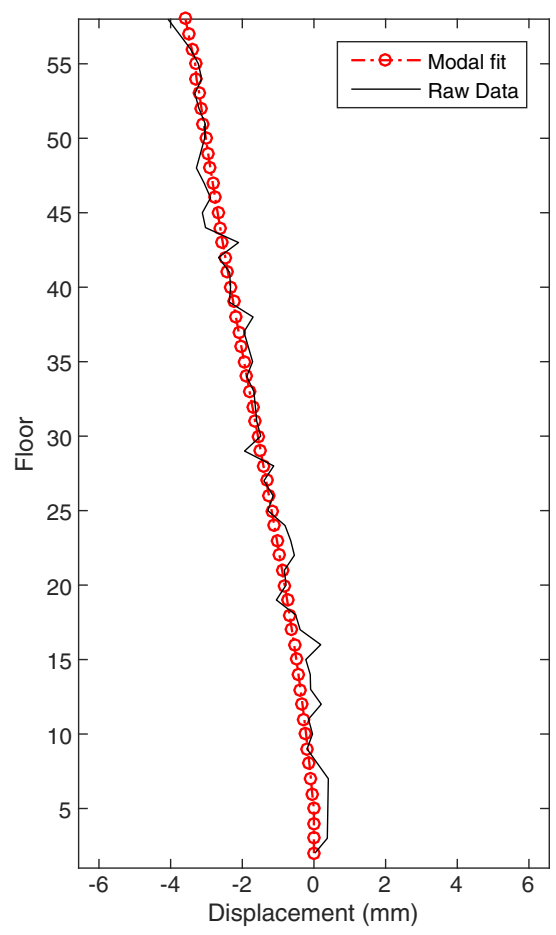

Figure 16. Relative displacement in north-south direction over the height of the building at an instantaneous time point during the 24 March 2015 wind gust event. Black curve: recorded observations. Red circles: smoothed approximation using the first five translational modes. Note that horizontal scale is different from that in Figure 13.

Our calculated values for pressure perturbations associated with the 24 March 2015 wind event at the building are in closer agreement with the maximum sustained wind speeds than the wind gust speeds. This is not surprising since for this wind event, the building responded almost entirely in its first eigenmode which is longer than most typical wind gusts (Beljaars 1987). Note that the wind speed data recorded by the NWS station were neither directly from the building site, nor from the same ground elevation or terrain; the NWS station is $\sim 18 \mathrm{~m}$ higher in ground elevation. For best characterization and comparison, local wind measurements from the building itself would be ideal. Observations such as these can be used to interpret wind-induced pressures as they vary with the height of the building, as well as floor-by-floor, to assess the environmental quality of the office space available (Islam et al. 1990, Irwin et al. 2013).

\section{CONCLUSIONS}

We report on an oil refinery explosion that was recorded by seismic stations with ground motions equivalent to a magnitude 2.0 earthquake. The refinery explosion also produced an air pressure wave that was recorded by an accelerometer array in a 52-story high-rise in downtown Los Angeles. This is the first known occurrence of a 
pressure wave having been recorded in an urban region, particularly with high spatial density, at small spatial scale within a single structure. The combined data sets from ground sensors and building sensors illustrate the value of densely instrumenting both the free field and buildings with the goal of providing assessments of strong shaking and structural damage from events such as earthquakes and explosions. A comprehensive investigation of the response of the crust-soil-structure system requires a seamless integration of observations distributed both horizontally in the ground or at ground level, and vertically in upper floors of buildings.

Anomalous acceleration energy pulses after the explosion were recorded on nearly every floor of the 52-story high-rise at a distance of $22.8 \mathrm{~km}$, resulting in an average source-receiver speed of $343 \mathrm{~m} / \mathrm{s}$. The coherent acceleration pulses are interpreted as the building's elastic response to a pressure wave propagating from the explosion site because the wave speed corresponded closely to the average speed of a pressure wave in air. The maximum absolute accelerations recorded in the building were $0.02 \% \mathrm{~g}$ and the maximum relative displacement was $0.03 \mathrm{~mm}$, after application of a digital broadband filter. Although we cannot completely rule out other sources for the anomalous accelerations, wind excitation is unlikely. Other data sets from the building show that the building responds predominantly in its first mode during moderate and high-level wind events.

We observe a force distribution due to the explosion pressure wave over a range of floors in the building, with a maximum amplitude of $1.42 \mathrm{kN}(0.32 \mathrm{kips})$ corresponding to a single floor. Distributing this force over the height and width of a typical floor gives a maximum average pressure perturbation of $7.7 \mathrm{~Pa}$. We find that a wind speed of $3.6 \mathrm{~m} / \mathrm{s}$ $(8 \mathrm{mph})$ would induce a similar pressure demand on the system. In the orthogonal horizontal direction, the maximum amplitude of the force was observed to be $1.1 \mathrm{kN}$ (0.24 kips) which translates into an average pressure perturbation of $5.8 \mathrm{~Pa}$. For general comparison, typical window glass breakage occurs for incident pressures of 1.034 to $1.517 \mathrm{kPa}$, minor damage occurs for 3.447 to $7.584 \mathrm{kPa}$, panels of sheet metal buckle for 7.584 to $12.410 \mathrm{kPa}$, and serious damage to steel frame buildings occurs for 27.579 to $48.263 \mathrm{kPa}$ (FEMA 426 2003). Thus, a pressure wave 100 times larger could have broken glass, and 1,000 times larger could possibly have had significant negative impact on the exterior of a structure.

\section{ACKNOWLEDGMENTS}

We appreciate discussions with Caltech Professor of Aeronautics and Mechanical Engineering Joseph Shepherd, and Caltech Professor of Planetary Science Andrew Ingersol who provided useful feedback on this study. We thank three anonymous reviewers whose comments improved this paper. We also thank the Betty and Gordon Moore Foundation, the Terrestrial Hazard Observation and Reporting Center at Caltech, and the Divisions of Geological and Planetary Science, and Engineering and Applied Science at Caltech for funding the development of the Community Seismic Network. The USGS Advanced National Seismic System and California Office of Emergency Services provided funding for SCSN operations. The Los Angeles/Long Beach Urban Area Security Initiative (UASI) funded a recent upgrade of the SCSN. 


\section{REFERENCES}

Beljaars, A. C. M., 1987. The influence of sampling and filtering on measured wind gusts, J. Atmospheric and Oceanic Technology 4, 613-626.

Cheng, M. H., Kohler, M. D., and Heaton, T. H., 2015. Prediction of wave propagation in buildings using data from a single seismometer, Bull. Seis. Soc. Am. 105, 107-119, doi: 10.1785/ 0120140037.

Chopra, A. K., 2012. Dynamics of Structures: Theory and Applications to Earthquake Engineering, Fourth Edition, Prentice Hall, Upper Saddle River, NJ, 944 pp.

Clayton, R., Heaton, T., Chandy, M., Krause, A., Kohler, M., Bunn, J., Guy, R., Olson, M., Faulkner, M., Cheng, M., Strand, L., Chandy, R., Obenshain, D., Liu, A., and Aivazis, M., 2011. Community Seismic Network, Annals of Geophysics 54, doi: 10.4401/ag-5269.

Clayton, R. W., Heaton, T., Kohler, M., Chandy, M., Guy, R., and Bunn, J., 2015. Community Seismic Network: A dense array to sense earthquake strong motions, Seis. Res. Lett. 86, 1354-1363, doi: 10.1785/0220150094.

ETABS, 1995. Structural and Earthquake Engineering Software, Computers and Structures, Inc., Berkeley, CA, www.csi.berkeley.com, available at http://docs.csiamerica.com/manuals/etabs/ Analysis\%20Reference.pdf.

Faulkner, M., Olson, M., Chandy, R., Krause, J., Chandy, K. M., and Krause, A., 2011. The next big one: Detecting earthquakes and other rare events from community-based sensors, Proceedings of the 10th ACM/IEEE International Conference on Information Processing in Sensor Networks, 12-14 April 2011, Chicago, IL.

Faulkner, M., Clayton, R., Heaton, T., Chandy, K. M., Kohler, M., Bunn, J., Guy, R., Liu, A., Olson, M., Cheng, M-H., and Krause, A., 2014. Community sense and response systems: your phone as quake detector, Communications of the Association for Computing Machinery (CACM) 57, doi: 10.1145/2622628.2622633.

Federal Emergency Management Agency (FEMA), 2003. Risk Management Series Reference Manual to Mitigate Potential Terrorist Attacks Against Buildings, FEMA 426, Washington, D.C., available at http://www.fema.gov/media-library-data/20130726-1455-20490-6222/ fema426.pdf.

Groom, N., 2015. Explosion at Exxon Mobil refinery in Torrance, California, injures four, Reuters, 18 February 2015, available at http://www.reuters.com/article/us-refineryblast-exxon-idUSKBNOLM1VR20150218.

Herrmann, R. B., 2013. Computer programs in seismology: An evolving tool for instruction and research, Seis. Res. Lett. 84, 1081-1088, doi: 10.1785/0220110096.

Holzer, T. L., Fletcher, J. B., Fuis, G. S., Ryberg, T., Brocher, T. M., and Dietel, C. M., 1996. Seismograms offer insight into Oklahoma City bombing, Eos, Transactions, American Geophysical Union 77, 393, 398-399.

Hsu, T., 2015a. State senators question Exxon Mobil over Torrance refinery explosion, Los Angeles Times, 6 March 2015, available at http://www.latimes.com/business/la-fi-exxontorrance-refinery-hearing-20150305-story.html.

Hsu, T., 2015b. U.S. investigates Torrance refinery explosion as contract talks resume, Los Angeles Times, 9 March 2015, available at http://www.latimes.com/business/la-fi-torrancerefinery-investigation-20150309-story.html.

Hutton, L. K., Woessner, J., and Hauksson, E., 2010. Seventy-seven years (1932-2009) of earthquake monitoring in southern California, Bull. Seis. Soc. Am. 100, 423-446; DOI: 10.1785/ 0120090130 . 
Irwin, P., Dennon, R., and Scott, D., 2013. Wind tunnel testing of high-rise buildings: an output of the CTBUH Wind Engineering Working Group, Council on Tall Buildings and Urban Habitat: Chicago.

Islam, M. S., Ellingwood, B., and Corotis, R. B., 1990. Dynamic response of tall buildings to stochastic wind load, J. Struct. Eng. 116, 2982-3002.

Kim, W-Y., Sykes, L. R., Armitage, J. H., Xie, J. K., Jacob, K. H., Richards, P. G., West, M., Waldhauser, F., Armbruster, J., Seeber, L., Du, W. X., and Lerner-Lam, A., 2001. Seismic waves generated by aircraft impacts and building collapses at World Trade Center, New York City, Eos, Transactions, American Geophysical Union 82, 565, 570-571.

Kinney, G. F., 1962. Explosive Shocks in Air, The Macmillan Co., New York, 198 pp.

Kohler, M. D., Heaton, T. H., and Bradford, S. C., 2007. Propagating waves recorded in the steel, moment-frame Factor building during earthquakes, Bull. Seis. Soc. Am. 97, 1334-1345, doi: $10.1785 / 0120060148$.

Kohler, M. D., Heaton, T. H., and Cheng, M. H., 2013. The Community Seismic Network and Quake-Catcher Network: Enabling structural health monitoring through instrumentation by community participants, Proceedings of the SPIE Smart Structures/Non-destructive Evaluation Conference, 10-14 March 2013, San Diego, CA.

Kohler, M. D., Heaton, T. H., Cheng, M. H., and Singh, P., 2014. Structural health monitoring through dense instrumentation by community participants: The Community Seismic Network and Quake-Catcher Network, $10^{\text {th }}$ U.S. National Conference on Earthquake Engineering (NC10EE), 21-25 July 2014, Anchorage, AK.

Koper, K. D., Wallace, T. C., and Hollnack, D., 1999. Seismic analysis of the 7 August 1998 truck-bomb blast at the American Embassy in Nairobi Kenya, Seis. Res. Lett. 70, 512-521.

Lamb, H., 1960. The Dynamical Theory of Sound, Second Edition, Dover Publication, New York, $307 \mathrm{pp}$.

Magistrale, H., Day, S., Clayton, R. W., and Graves, R., 2000. The SCEC southern California reference three-dimensional seismic velocity model version 2, Bull. Seis. Soc. Am. 90, S65-S76.

Olson, M., Liu, A., Faulkner, M., and Chandy, K. M., 2011. Rapid detection of rare geospatial events: earthquake warning applications, Proceedings of the Fifth ACM International Conference on Distributed Event-Based Systems, New York.

Penn, I., 2016. Exxon Mobil asserts Torrance plant is safe, Los Angeles Times, 14 January 2016, available at http://www.latimes.com/business/la-fi-exxon-mobil-torrance-20160113-story.html.

Prieto, G. A., Lawrence, J. F., Chung, A. I., and Kohler, M. D., 2010. Predicting earthquake response of civil structures from ambient noise, Bull. Seis. Soc. Am. 100, 2322-2328, doi: 10.1785/0120090285.

Shaw, J. H., Plesch, A., Tape, C., Suess, M. P., Jordan, T., Ely, G., Hauksson, E., Tromp, J., Tanimoto, T., Graves, R., Olsen, K., Nicholson, C., Maechling, P., Rivero, C., Lovely, P., Brankman, C. M., and Munster, J., 2015. Unified Structural Representation of the southern California crust and upper mantle, Earth and Planetary Science Letters, 415, 1-15.

Taranath, B. S., 1997. Steel, Concrete, and Composite Design of Tall Buildings, Second Edition, McGraw-Hill, San Francisco.

Wunderground, 2015. Wunderground Personal Weather Station KCALOSAN8, available at http://www.wunderground.com/personal-weather-station/dashboard?ID=KCALOSAN8 \&scrollTo=historyTable\#history/s20150324/e20150324/mdaily.

(Received 23 June 2015; accepted 20 January 2016) 